\title{
Bis-Sulfone- and Bis-Sulfoxide-Spirobifluorenes: Polar Acceptor Hosts with Tunable Solubilities for Blue-Phosphorescent Light- Emitting Devices
}

\author{
Cathrin D. Ertl, ${ }^{[a]}$ Henk J. Bolink,${ }^{[b]}$ Catherine E. Housecroft, ${ }^{*[a]}$ Edwin C. Constable, ${ }^{[a]}$ Enrique Ortí, ${ }^{[b]}$ \\ José M. Junquera-Hernández, ${ }^{[b]}$ Markus Neuburger, ${ }^{[a]}$ Nail M. Shavaleev, ${ }^{[c]}$ Mohammad Khaja \\ Nazeeruddin ${ }^{[c]}$ and David Vonlanthen ${ }^{\star[a, b, d]}$
}

\begin{abstract}
Bis-sulfone- and bis-sulfoxide-spirobifluorenes are a promising class of high-triplet-energy electron-acceptor hosts for blue phosphorescent light-emitting devices. The molecular design and synthetic route are simple and facilitate tailoring of the solubilities of the host materials without lowering the high-energy triplet state. The syntheses and characterization (including single crystal structures) of four electron-accepting hosts are reported; the trend in their reduction potentials is consistent with the electronwithdrawing nature of the sulfone or sulfoxide substituents. Emission maxima of 421-432 nm overlap with the MLCT absorption of the sky-blue emitter bis(4,6-difluorophenylpyridinato)(picolinato)iridium(III) (FIrpic), allowing effective energy transfer from the acceptor hosts to Flrpic. Theoretical calculations show that the introduction of sulfone groups leads to better electron acceptors compared to analogous phosphine oxide functionalized hosts and, at the same time, preserves the energy of the lowestlying triplet above that of the FIrpic emitter. The new hosts have been tested in phosphorescent light-emitting electrochemical cells (LECs). Large effects of the various solubilizing moieties on the device performance are observed and discussed.
\end{abstract}

[a] C. D. Ertl, Prof. Dr. C. E. Housecroft, ${ }^{*}$ Prof. Dr. E. C. Constable, Dr M. Neuburger, Dr. D. Vonlanthen*

Department of Chemistry, University of Basel, Spitalstrasse 51 4056 Basel (Switzerland)

E-mail: catherine.housecroft@unibas.ch

[b] Dr. H. J. Bolink, Prof. Dr. E. Ortí, Dr. D. Vonlanthen, Dr. J. M. Junquera-Hernández

Instituto de Ciencia Molecular, Universidad de Valencia, 46980 Paterna (Spain)

[c] Dr. N. M. Shavaleev, Prof. M. K. Nazeeruddin

Group for molecular Engineering of functional materials, Institute of Chemical Sciences and Engineering, École Polytechnique Fédérale de Lausanne, $\mathrm{CH}-1951$ Sion (Switzerland)

[d] Current Address: Dr. D. Vonlanthen

Center for Polymers \& Organic Solids, University of California Santa Barbara, Santa Barbara, CA 93106-5090 (USA)

E-mail: dvl@physics.ucsb.edu

Supporting information for this article is available on the WWW under http://www.chemeurj.org/ or from the author.

\section{Introduction}

Organic light-emitting diodes (OLEDs) promise to have a great potential for thin flat-panel displays and general lighting in the forthcoming future. ${ }^{[1]}$ In phosphorescent OLEDs, host materials transfer energy from singlet and triplet states to the phosphor resulting theoretically in $100 \%$ internal quantum efficiency. ${ }^{\text {[2] }}$

Good electron-acceptor host materials for blue and white electroluminescent devices possess high triplet energy, good electron-transport properties, and improve the electron injection. ${ }^{[1 a]}$ However, the limited availability of electrontransporting host materials, in particular those that are suitable for solution processing, is one of the bottlenecks to providing cheap, economically competitive, white electroluminescent devices. Phosphine oxide (PO) functionalization of biphenyl-type structures has proved to be a good strategy to obtain hightriplet-energy electron-acceptor host materials with low-lying LUMOs. ${ }^{[3]}$ Highly efficient blue and white multi-stack OLEDs using various $\mathrm{PO}$-acceptor hosts have been reported. ${ }^{[4]}$ Moreover, the polar PO group can be used in modifiers to lower the work function of metal electrodes. ${ }^{[5]}$ We have recently reported the advantage of a PO-acceptor host in phosphorescent light-emitting electrochemical cell (LEC) devices. ${ }^{[6]}$

Kippelen and coworkers have shown that bis-sulfonylbiphenyl is a good acceptor host for blue OLEDs. ${ }^{[7]}$ The sulfone group lowers the LUMO energy more than the PO group. ${ }^{[7]}$ Sasabe et al ${ }^{[8]}$ have recently used a terphenyl-sulfone derivative to obtain highly-efficient blue multi-layer OLEDs. However, the low solubility of these hosts coupled with the multi-layer device architecture requires the use of expensive vapor-deposition techniques.

The introduction of sulfone and sulfoxide groups in host structure ${ }^{[9]}$ is attractive for several reasons: $i$ ) the acceptor groups exert a strong inductive electron-withdrawing effect, which lowers both the HOMO and LUMO energies of the triplet synthon and improves electron injection; ii) the heteroatom interrupts conjugation to neighboring $\pi$-systems and preserves the high-energy triplet of the host; iii) molecules with strongly polarized SO bonds can be expected to function as electrode modifiers analogously to those bearing PO groups: $;^{[5]}$ iv) the simplicity and broad scope of the sulfone/sulfoxide chemistry is highly appealing. ${ }^{[7,10]}$

Here we report the design, synthesis, and photophysical and electrochemical properties of four electron-acceptor hosts: 
SPSO1, SPSO2, SPSO3, and SPSX (Scheme 1). The experimental study is complemented by theoretical calculations. The sulfoxide functionalization (not previously reported in host materials in LECs) should give rise to higher-energy triplet materials. ${ }^{[11]}$ The new hosts were tested in LECs, and the influence of the various solubilizing moieties on the photophysical properties and the LEC performance was investigated. The spirobifluorene moiety is generally preferred over smaller biphenyl structures as it leads to more stable amorphous thin-film structures. ${ }^{[12]}$ However, the structural rigidity of spirobifluorenes tends to hamper solution processing.
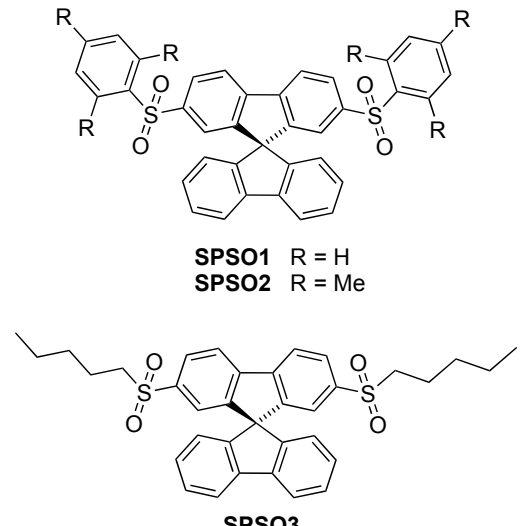

SPSO3

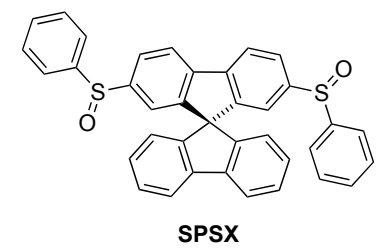

Scheme 1. Chemical structures of the electron-acceptor host compounds.

\section{Results and Discussion}

Synthesis and NMR spectroscopic characterization: All hosts were synthesized from the commercially available 2,7dibromo-9,9'-spirobifluorene. Reaction with the appropriate thiol yielded the bis-thioether derivatives 1-3 (Scheme 2) which were subsequently oxidized to the final acceptor hosts. The top reaction ${ }^{[13]}$ in Scheme 2 was achieved through either aromatic nucleophilic $\left(\mathrm{S}_{\mathrm{N}} \mathrm{Ar}\right)$ substitution (method $a$ ) or Pd-cross-coupling (method $b$, see the Supporting Information) to give $\mathbf{1}$ in good yield. Alternatively, 1 was synthesized starting from 2,7bis(phenylthio)-9H-fluoren-9-one $\quad(4, \quad$ see the Supporting Information). We note that $\mathbf{4}$ can also be used to design mixed $\mathrm{n}$ - and p-type high-energy triplet cores. ${ }^{[10]}$ Compound 4 was treated with biphenyl-2-yl magnesium bromide to give 1 in $44 \%$ over 3 steps (method $c$, see the Supporting Information).

Due to its simplicity, the $S_{N} A r$ reaction (method $a$ in Scheme 2) was preferred over the transition-metal catalyzed reaction to give the bis-thioethers. Thus, compounds $\mathbf{2}$ and $\mathbf{3}$ were obtained by applying the $S_{N} A r$ method (Scheme 2). However, the Pdcatalyzed cross-coupling methodology offers a viable alternative if the thiol precursor is not readily accessible. A long reaction

time was required to obtain 2 , probably due to the steric hindrance of the mesitylene- $\mathrm{CH}_{3}$ groups in ortho-position.
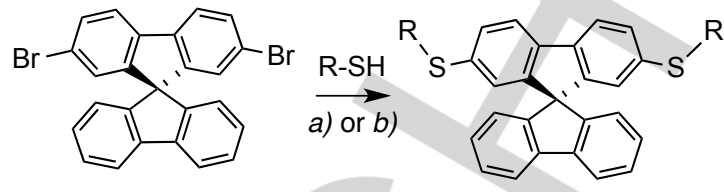

1) 2-Bromobiphenyl, $\mathrm{Mg}, \mathrm{Et}_{2} \mathrm{O}$

2) aq. $\mathrm{HCl} / \mathrm{AcOH}$ $44 \%$ (3 steps)

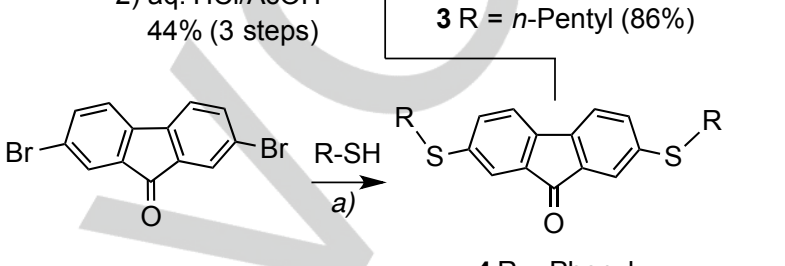

$4 \mathrm{R}=$ Phenyl

a) $\mathrm{K}_{2} \mathrm{CO}_{3}, \mathrm{DMF}$; b) $\mathrm{Pd}_{2}(d b a)_{3}$, xantphos; $\mathrm{K}_{2} \mathrm{CO}_{3}, p$-xylene

Scheme 2. Synthetic routes to obtain the thioethers

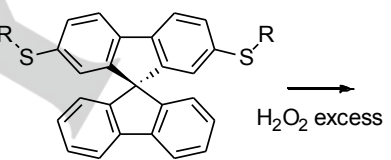

bis-thioethers 1-3

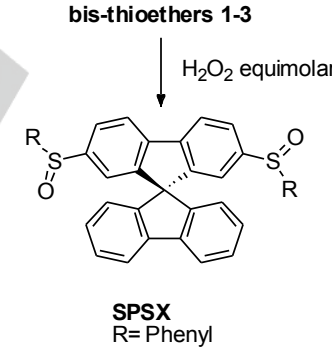

Scheme 3. Selective oxidation of the various thioethers. Reaction conditions are listed in Table 1.

To afford the final acceptor hosts, different oxidation conditions were tested (Table 1). Selective and stepwise oxidation of the symmetric bis-thioethers 1-3 gave the bissulfoxide SPSX and the bis-sulfones SPSO1, SPSO2, and SPSO3 (Scheme 3). All hosts were obtained by metal-catalystfree oxidation reactions using $\mathrm{H}_{2} \mathrm{O}_{2}$ or mCPBA as oxidant.

Selective oxidation ${ }^{[14]}$ of 1 with an equimolar amount of $\mathrm{H}_{2} \mathrm{O}_{2}$ at room temperature gave the bis-sulfoxide SPSX. The presence of two stereogenic sulfur centers leads to the formation of the enantiomeric $R, R$ - and $S, S$-pair and the $R, S$-meso-form. The ${ }^{1} \mathrm{H}$ and ${ }^{13} \mathrm{C}$ NMR spectroscopic data show that SPSX exists as a 1 : 1 mixture of diastereoisomers $(R, R / S, S$ and meso), consistent with there being no inversion at sulfur on the NMR spectroscopic 
timescale at $295 \mathrm{~K}$. Oxidation of bis-thioether 1 with $\mathrm{mCPBA}^{[15]}$ was not as selective giving the asymmetric sulfone side-product 5 (see the Supporting Information). Treatment of $\mathbf{1}$ with an excess of $\mathrm{H}_{2} \mathrm{O}_{2}$ gave exclusively the bis-sulfone SPSO1 in high yield. High temperatures decreased the reaction time and led to higher yields of 1 .

\begin{tabular}{|c|c|c|c|}
\hline Substrate & Oxidant & Solvent/Conditions ${ }^{[\mathrm{b}]}$ & $\begin{array}{l}\text { Host } \\
\text { (Yield, \%) }\end{array}$ \\
\hline 1 & $\mathrm{H}_{2} \mathrm{O}_{2}(2.0)$ & $A$, r.t. $(30 \mathrm{~h})$ & $\begin{array}{l}\text { SPSX (70) } \\
\text { SPSX (47) }\end{array}$ \\
\hline 1 & mCPBA (2.0) & $B, 0^{\circ} \mathrm{C}$, then r.t. & SPSO1 (77) \\
\hline 1 & $\mathrm{H}_{2} \mathrm{O}_{2}$ (exc.) & $A$, r.t. $(21 \mathrm{~h})$ & SPSO1 (89) \\
\hline 1 & $\mathrm{H}_{2} \mathrm{O}_{2}$ (exc.) & $A$, reflux $(3.5 \mathrm{~h})$ & SPSO2 (63) \\
\hline & $\mathrm{H}_{2} \mathrm{O}_{2}$ (exc.) & $C$, reflux $(18 \mathrm{~h})$ & SPSO3 (55) \\
\hline 2 & $\mathrm{H}_{2} \mathrm{O}_{2}$ (exc.) & $A$, r.t. $(24 \mathrm{~h})$ & \\
\hline 3 & & then $40^{\circ} \mathrm{C}(0.5 \mathrm{~h})$ & \\
\hline
\end{tabular}

[a] Entries 1, 4-6 in the table are described in the main paper; entries 2 and 3 are given in the Supporting Information. [b] Solvent systems: $A=A c O H$ $\left(\mathrm{CHCl}_{3}\right), B=\mathrm{CH}_{2} \mathrm{Cl}_{2}, \mathrm{C}=\mathrm{AcOH} / \mathrm{EtOAc}$

Oxidation of 2 afforded the bis-mesitylsulfone SPSO2 in good yield. Similarly, oxidation of $\mathbf{3}$ gave SPSO3 in satisfactory yield. While conversions of 1 and 3 required the use of chlorinated solvents during the oxidation, oxidation of 2 to SPSO2 proceeded smoothly in ethyl acetate. This points to the improved solubilizing effect of the mesityl group. All new compounds were fully characterized by ${ }^{1} \mathrm{H}$ and ${ }^{13} \mathrm{C}$ NMR and IR spectroscopies, mass spectrometry and elemental analysis.

Crystal structures of SPSO1.2 $\mathrm{CH}_{2} \mathrm{Cl}_{2}$, SPSO2, and SPSO3: Single crystals of SPSO1.2 $\mathrm{CH}_{2} \mathrm{Cl}_{2}$ were grown from $\mathrm{CH}_{2} \mathrm{Cl}_{2}$ overlaid with $\mathrm{MeOH}$. X-ray quality crystals of SPSO2 were obtained from a recrystallization of the bulk material from cyclohexane and toluene, and those of SPSO3 were grown from a $\mathrm{CHCl}_{3}$ solution of the compound overlaid with n-hexane. The structures of the three compounds were determined by single crystal X-ray diffraction. SPSO1.2 $2 \mathrm{CH}_{2} \mathrm{Cl}_{2}$ crystallizes in the space group $P 2_{1} / c$ with one molecule and two disordered $\mathrm{CH}_{2} \mathrm{Cl}_{2}$ molecules in the asymmetric unit. Each solvent molecule has been modeled over two positions with fractional occupancies of $0.70 / 0.30$ and $0.84 / 0.16$ respectively. Figure $1 \mathrm{a}$ shows the structure of the SPSO1 molecule with selected bond parameters given in the figure caption. SPSO2 and SPSO3 both crystallize in the $C 2 / c$ space group with half the molecule in the asymmetric unit; the second half is generated by a 2 -fold axis (Figure $1 \mathrm{~b}$ and 1c).

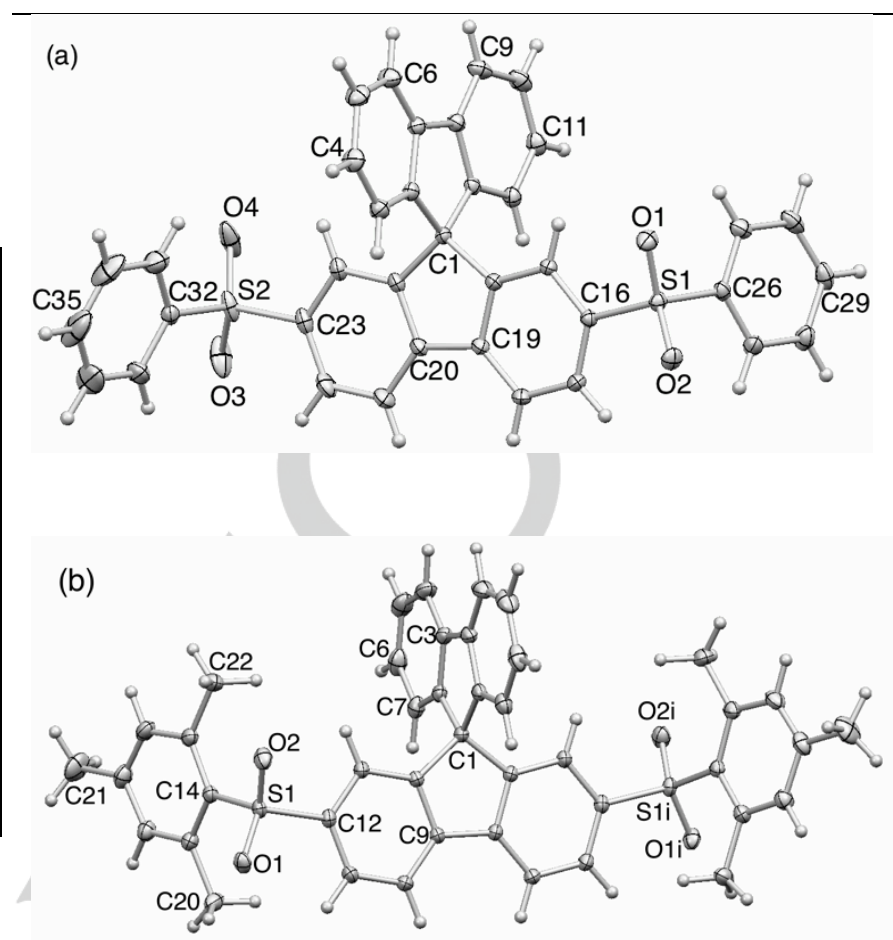

(c)

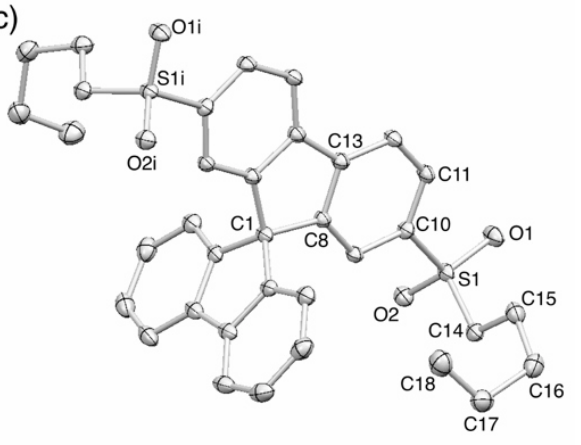

Figure 1. X-ray structures of (a) SPSO1 in SPSO1.2 $\mathrm{CH}_{2} \mathrm{Cl}_{2}$, (b) SPSO2, and (c) SPSO3. Solvent molecules are omitted for clarity. Ellipsoids plotted at the $40 \%$ probability level. Selected bond parameters: SPSO1: S1-O1 = 1.4419(13), S1-O2 = 1.4429(12), S2-O3 = 1.4347(17), S2-O4 = 1.4417(18), $\mathrm{C} 16-\mathrm{S} 1=1.7626(15), \mathrm{C} 26-\mathrm{S} 1=1.7632(16), \mathrm{C} 23-\mathrm{S} 2=1.7679(17), \mathrm{C} 32-\mathrm{S} 2$ $=1.7563(17) \AA ; \mathrm{C} 26-\mathrm{S} 1-\mathrm{C} 16=105.72(7), \mathrm{C} 26-\mathrm{S} 1-\mathrm{O} 1=108.05(8)$, $\mathrm{C} 16-\mathrm{S} 1-\mathrm{O} 1=107.73(7), \mathrm{C} 26-\mathrm{S} 1-\mathrm{O} 2=107.78(7), \mathrm{C} 16-\mathrm{S} 1-\mathrm{O} 2=107.25(7)$, $\mathrm{O} 1-\mathrm{S} 1-\mathrm{O} 2=119.52(8), \mathrm{C} 23-\mathrm{S} 2-\mathrm{C} 32=105.08(8), \mathrm{C} 23-\mathrm{S} 2-\mathrm{O} 3=$ 107.33(10), C32-S2-O3 = 108.37(9), C23-S2-O4 =107.73(9), C32-S2-O4 = 107.37(10), O3-S2-O4 = 120.02(12) $;$ SPSO2: S1-O1 = 1.4389(10), S1-O2 $=1.4373(10), \mathrm{C} 12-\mathrm{S} 1=1.7753(12), \mathrm{C} 14-\mathrm{S} 1=1.7859(13) \AA \mathrm{A} ; \mathrm{C} 14-\mathrm{S} 1-\mathrm{C} 12=$ 106.93(6), $\mathrm{C} 14-\mathrm{S} 1-\mathrm{O} 1=107.60(6), \mathrm{C} 12-\mathrm{S} 1-\mathrm{O} 1=107.70(6), \mathrm{C} 14-\mathrm{S} 1-\mathrm{O} 2=$ 109.28(6), C12-S1-O2 = 107.09(6), O1-S1-O2 = 117.75(6) ${ }^{\circ}$ (symmetry code $\mathrm{i}=-x, y, 1 / 2-z)$. SPSO3: S1-O $1=1.4406(11), \mathrm{S} 1-\mathrm{O} 2=1.4427(12), \mathrm{C} 10-\mathrm{S} 1$ $=1.7808(15), \quad C 14-S 1=1.7705(17) \AA ; \quad C 14-S 1-C 10=103.69(7)$, $\mathrm{C} 14-\mathrm{S} 1-\mathrm{O} 1=109.70(7), \mathrm{C} 10-\mathrm{S} 1-\mathrm{O} 1=108.16(7), \mathrm{C} 14-\mathrm{S} 1-\mathrm{O} 2=107.74(7)$, $\mathrm{C} 10-\mathrm{S} 1-\mathrm{O} 2=108.13(7), \mathrm{O} 1-\mathrm{S} 1-\mathrm{O} 2=118.43(7)^{\circ}($ symmetry code $\mathrm{i}=1-x, y$, $1 / 2-Z$ ). 
The X-ray diffraction data confirm that the compounds possess the expected structures, with bond parameters that are similar to one another and which are consistent with other organic sulfones. ${ }^{[16]}$ Dominant packing interactions in SPSO1 $2 \mathrm{CH}_{2} \mathrm{Cl}_{2}$ involve short $\mathrm{S}-\mathrm{O} \cdots \mathrm{HC}$ and $\mathrm{Cl} \cdots \mathrm{HC}$ contacts. In addition to exhibiting short SO $\cdots$ HC contacts of $2.51 \AA$, molecules of SPSO2 pack so that centrosymmetric pairs of fluorene domains interact through weak face-to-face $\pi$ interactions (Figure 2). Although the interplane separation is 3.1 $\AA$, the inter-centroid distance between arene rings is too large $(4.9 \AA)$ for this to be more than a very weak contact. Short $\mathrm{S}-\mathrm{O} \cdots \mathrm{HC}$ contacts are also a dominant feature of the molecular packing in SPSO3. The $n$-pentyl chain is in a partially folded conformation and is accommodated in a cleft between two fluorene domains of adjacent molecules (Figure 3). Short $\mathrm{CH}^{\cdots} \pi$ contacts operate between the two methylene units and the arene ring (Figure 3).

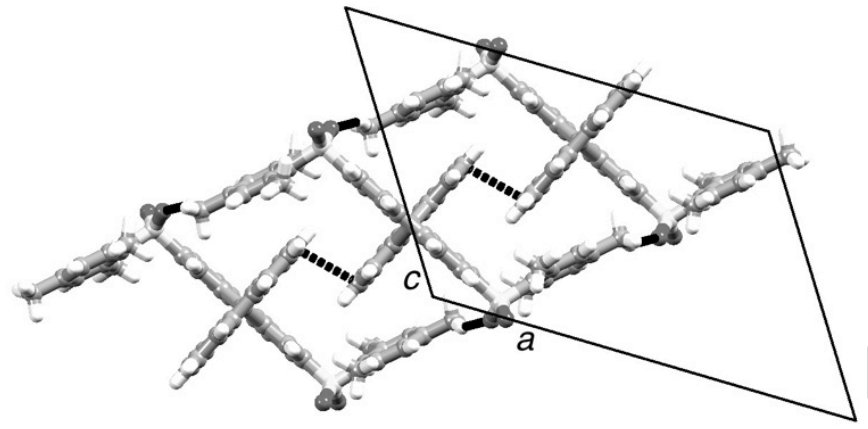

Figure 2. Packing of molecules of SPSO2 showing short S-O $\cdots \mathrm{HC}$ and $\pi-$ contacts (see text) in black hashed lines.

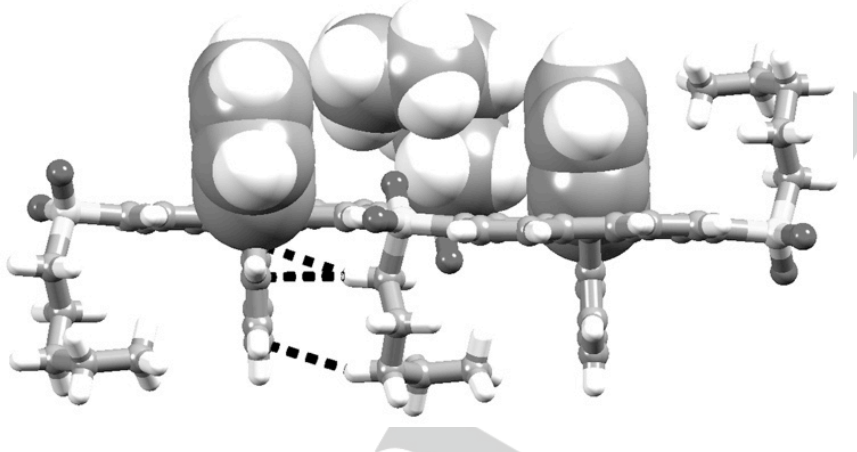

Figure 3. Packing of molecules of SPSO3 showing sandwiching of the folded $n$ - pentyl chains between pairs of fluorene domains of adjacent molecules. Short $\mathrm{CH} \cdots \pi$-contacts are shown by black hashed lines.

Electrochemical and photophysical studies: Reversible reduction processes were observed for compounds SPSO1-3 at similar potentials $\left(E_{1 / 2}{ }^{\text {red }}\right.$, Table 2 and Figure 4$)$. This is in agreement with the Hammett constants reported for $\mathrm{SO}_{2}$-aryl$(\sigma=0.68)$ and $\mathrm{SO}_{2}$-alkyl-substituents $(\sigma=0.72-0.77)$ indicating a similar electron-withdrawing strength for both groups. ${ }^{[17]}$ In contrast, $E_{1 / 2}{ }^{\text {red }}$ for SPSX is shifted to more negative potential (Figure 4 and Table 2).
Table 2. Photophysical and electrochemical data

\begin{tabular}{llll} 
Host & $E_{1 / 2}{ }^{\text {red }[\mathrm{ab}]}(\mathrm{V})$ & $\lambda_{\mathrm{abs}}{ }^{[\mathrm{b}]}(\mathrm{nm})$ & $\lambda_{\mathrm{em}}{ }^{[\mathrm{b}]}(\mathrm{nm}, \mathrm{eV})$ \\
\hline SPSO1 & -2.00 & 284,330 & $432,2.87$ \\
SPSO2 & -2.07 & 285,327 & $421,2.95$ \\
SPSO3 & -2.12 & 279,322 & $422,2.94$ \\
SPSX & -2.24 & 273,326 & $380,3.26$ \\
\hline
\end{tabular}

[a] First reduction wave, measured in $\mathrm{CH}_{3} \mathrm{CN}$ with $\left[\mathrm{TBA}^{+}\left[\mathrm{PF}_{6}\right]^{-}\right.$against $\mathrm{Fc} / \mathrm{FC}^{+}$ as internal reference. [b] Measured in $\mathrm{CH}_{3} \mathrm{CN}$ at $298 \mathrm{~K}\left(1 \times 10^{-5} \mathrm{M}\right)$.

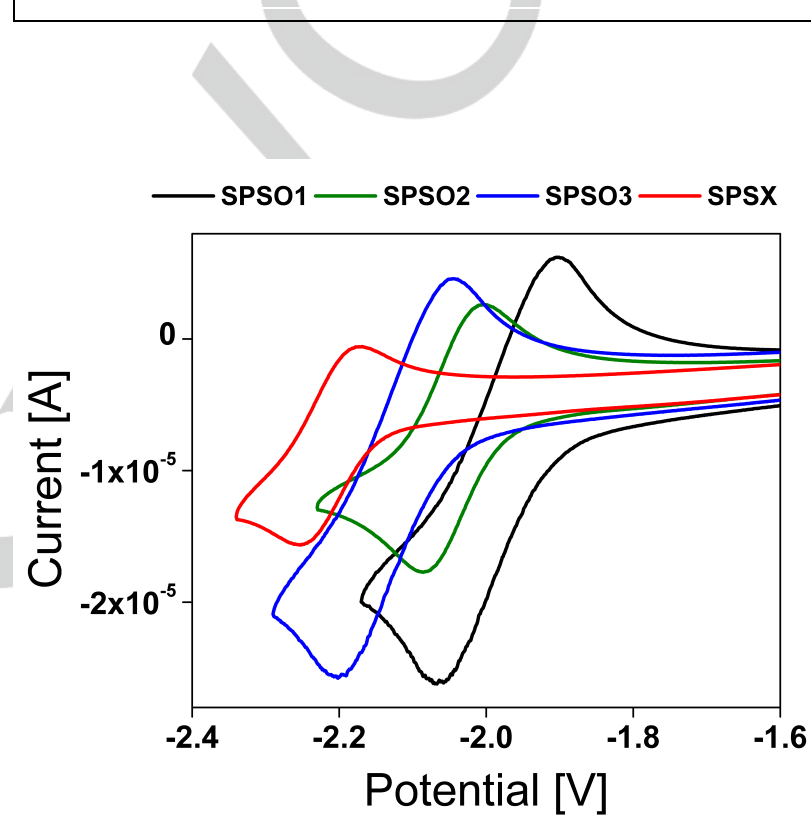

Figure 4. Cyclic voltammograms of SPSO1-3 and SPSX in $\mathrm{CH}_{3} \mathrm{CN}$ with $\left[\mathrm{TBA}^{+}\left[\mathrm{PF}_{6}\right]^{-}\right.$against $\mathrm{Fc} / \mathrm{Fc}^{+}$(as internal reference).

The absorption and the photoluminescence $(\mathrm{PL})$ spectra of the sulfoxide and sulfone hosts are shown in Figure 5 . The structured absorption observed above $270 \mathrm{~nm}$ for all four compounds is attributed to $\pi \rightarrow \pi^{*}$ transitions centered on the spirobifluorene core. The bis-sulfonyl-functionalized hosts exhibit very similar PL spectra with a maximum emission, $\lambda_{\mathrm{em}}$, in the range of $421-432 \mathrm{~nm}$. This emission overlaps well with the This emission overlaps well with the metal-to-ligand charge transfer (MLCT) absorption of the sky-blue emitter bis(4,6difluorophenylpyridinato)(picolinato)iridium(III) $\quad$ (FIrpic), ${ }^{[18]}$ enabling efficient energy transfer from the bis-sulfone acceptor hosts to Flrpic. ${ }^{[7]}$ The PL emission maxima of the bis-sulfoxide SPSX is shifted by $50 \mathrm{~nm}$ into the deep-blue/near-UV compared to the bis-sulfones. ${ }^{[11]}$ 


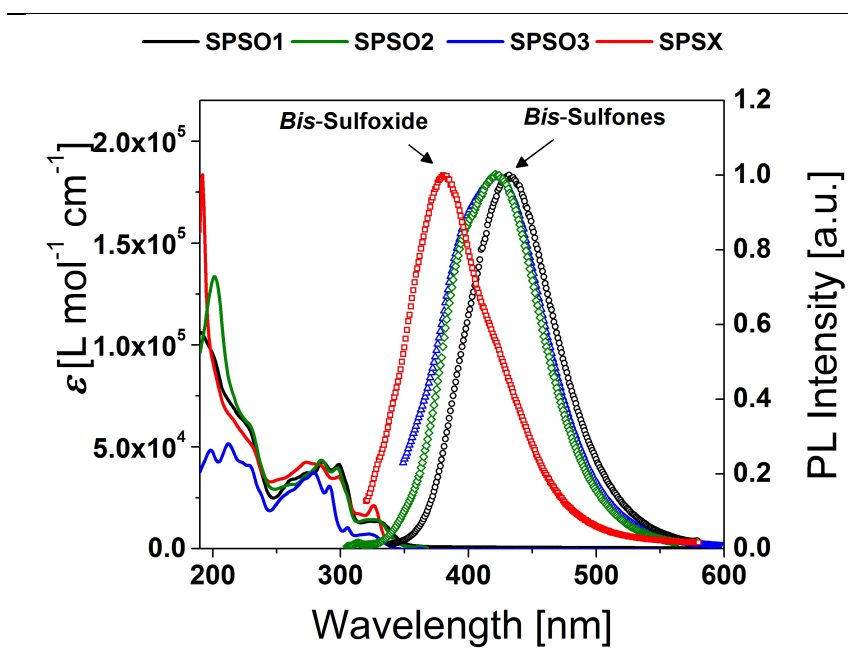

Figure 5. UV and PL spectra of SPSO1-3 and SPSX in $\mathrm{CH}_{3} \mathrm{CN}$. Solution concentrations $=1.0 \times 10^{-5} \mathrm{~mol} \mathrm{dm}^{-3}$.

Theoretical calculations: To gain further insight into the electrochemical and photophysical properties, the molecular and electronic structures of the sulfoxide and sulfone hosts were investigated by performing density functional theory (DFT) calculations at the B3LYP/6-31G** level in the presence of the solvent (acetonitrile). The non-substituted 9,9'-spirobifluorene molecule (SP) and the 2,7-bis(diphenylphosphoryl)-9,9'spirobifluorene phosphine oxide (SPPO13) were also calculated at the same theoretical level as reference systems for comparison purposes.

The molecular geometries of the substituted systems were fully relaxed with the two substituent groups pointing to different sides of the fluorene plane to which they are attached and converged to $C_{2}$-symmetry conformations (see Figure $S 1$ in the Supporting Information). Calculations correctly reproduce the structural features obtained from X-ray single-crystal analysis for SPSO1-3. The fluorene moieties are almost orthogonal forming dihedral angles of about $88.5^{\circ}$ and the sulfone groups exhibit near-tetrahedral structures. For instance, SPSO1 is computed to have average $\mathrm{C}-\mathrm{S}-\mathrm{C}, \mathrm{C}-\mathrm{S}-\mathrm{O}$, and $\mathrm{O}-\mathrm{S}-\mathrm{O}$ bond angles of $105.85,107.58$, and $119.87^{\circ}$, respectively, in very good accord with the experimental X-ray average values $(105.40,107.70$, and $119.77^{\circ}$, respectively). Calculations predict a linearly extended conformation for the $n$-pentyl chains attached to the sulfur atoms in the SPSO3 molecule. The folded conformation observed experimentally (Figure 1c) is stabilized by the interaction between adjacent molecules.

Figure 6 compares the electron density contours calculated for the highest-occupied (HOMO) and lowest-unoccupied molecular orbital (LUMO) of SPSO1, as a representative example, with those computed for non-substituted spirobifluorene. The topology of the frontier MOs of all the other hosts is similar to that depicted for SPSO1 (see Figure S2 in the Supporting Information). Table 3 collects the energies calculated for the HOMO, the LUMO, and the HOMO-LUMO gap for all the hosts and SP. It also includes the electron affinities computed as the energy difference between the neutral host and its radical anion at their respective minimum-energy optimized geometries.

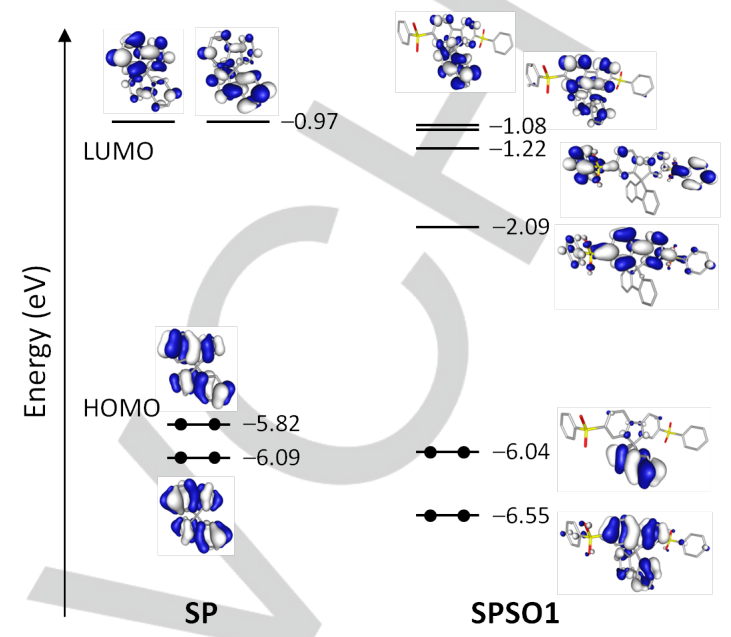

Figure 6. Schematic representation showing the isovalue contours $( \pm 0.03$ a.u.) and energies calculated for the frontier molecular orbitals of SP and SPSO1. Hydrogen atoms are omitted.

Table 3. B $3 L Y P / 6-31 G^{* *}$ values computed for the energy of the HOM $\left(E_{\text {Hомо }}\right)$ and the LUMO ( $\left.E_{\text {LUMO }}\right)$, the HOMO-LUMO energy gap $\left(\Delta E_{\mathrm{H}-\mathrm{L}}\right)$, an the electron affinity (EA). All values are in $\mathrm{eV}$.

\begin{tabular}{|lcccc} 
Host & $E_{\text {номо }}$ & $E_{\text {LUмо }}$ & $\Delta E_{\text {Номо-цUмо }}$ & EA \\
\hline SP & -5.82 & -0.97 & 4.85 & 1.20 \\
SPSO1 & -6.04 & -2.09 & 3.95 & 2.39 \\
SPSO2 & -6.02 & -1.95 & 4.07 & 2.29 \\
SPSO3 & -6.04 & -1.97 & 4.07 & 2.28 \\
SPSX & -5.95 & -1.62 & 4.33 & 2.09 \\
SPP013 & -5.98 & -1.73 & 4.25 & 2.02 \\
\hline
\end{tabular}

The SP molecule presents a $D_{2 d}$ symmetry with two equivalent fluorene moieties over which molecular orbitals are equally distributed. Functionalization lowers the molecular symmetry and breaks the equivalence of the fluorene moieties. As observed in Figure 6 for SPSO1, the LUMO in the host is fully localized on the fluorene to which the sulfone groups are attached, whereas the HOMO mainly resides on the nonfunctionalized fluorene. This suggests that, upon reduction, electron injection takes place on the functionalized fluorene fragment. This is illustrated in Figure 7 for SPS01, for which the unpaired electron in the anion is fully localized on the substituted fragment. 


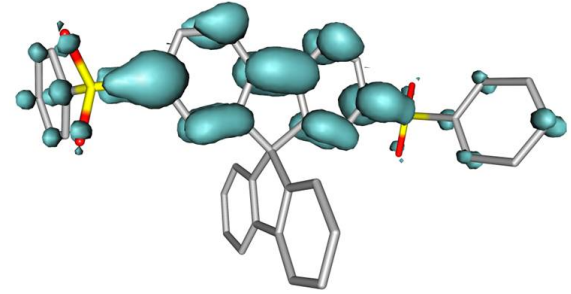

Figure 7. Unpaired-electron spin density contours (0.002 a.u.) calculated for the anion of SPSO1.

Functionalization with electron-withdrawing sulfone groups determines a drastic stabilization of the LUMO that lowers in energy from $-0.97 \mathrm{eV}$ in SP to $-2.09 \mathrm{eV}$ in SPSO1. The stabilization of the HOMO is significantly smaller $(0.22 \mathrm{eV})$ because the sulfone groups do not participate in this orbital (Figure 6). The HOMO-LUMO gap therefore decreases by almost $1 \mathrm{eV}$ in passing from SP $(4.85 \mathrm{eV})$ to SPSO1 $(3.94 \mathrm{eV})$. Compared to SPPO13 bearing phosphine PO groups, the sulfone $\mathrm{SO}_{2}$ groups in SPSO1 lower the energy of the LUMO in a higher degree $(-2.09$ vs. $-1.73 \mathrm{eV})$ and leads to a higher electron affinity (2.39 vs. $2.02 \mathrm{eV})$. This supports the results previously found for biphenyl-based hosts, ${ }^{[7]}$ and confirms the higher electron-withdrawing character of the sulfone group compared with the phosphine group.

The LUMO of SPSO2 $(-1.95 \mathrm{eV})$ and SPSO3 $(-1.97 \mathrm{eV})$ are calculated to be slightly higher in energy than the LUMO of SPSO1 $(-2.09 \mathrm{eV})$. The destabilization is due to the fact that this orbital is delocalized over the terminal phenyl groups for SPSO1 (Figure 6), whereas it remains more confined over the fluorene moiety for SPSO2 and especially for SPSO3 (Figure S2). This suggests that SPSO1 presents a more effective electronic conjugation through the sulfone groups than SPSO2 and SPSO3. The sulfoxide groups in SPSX exert a weaker electronwithdrawing effect than the sulfone groups and, as a consequence, induce a smaller stabilization of the LUMO that is calculated at $-1.62 \mathrm{eV}$. The computed electron affinity decreases along the series SPSO1 $(2.39 \mathrm{eV})>$ SPSO2 $(2.29$ $\mathrm{eV})>$ SPSO3 $(2.28 \mathrm{eV})>$ SPSX $(2.09 \mathrm{eV})$ in good agreement with the more negative reduction potentials measured along this series $(-2.00,-2.07,-2.12$, and $-2.24 \mathrm{~V}$, respectively, Table 2$)$. The values obtained for the electron affinities suggest that the sulfone and sulfoxide hosts are better electron acceptors than the phosphine oxide SPPO13 host for which an EA of $2.02 \mathrm{eV}$ is computed. Owing to the almost constant energy of the HOMO (Table 3), the HOMO-LUMO gap increases along the series SPSO1 $(3.95 \mathrm{eV})<$ SPSO2 $(4.07 \mathrm{eV})<$ SPSO3 $(4.07 \mathrm{eV})<$ SPSX $(4.33 \mathrm{eV})$ pointing to a blue shift of the absorption and emission wavelengths along the series.

Time dependent DFT (TD-DFT) calculations were performed on the geometry of the electronic ground state $\left(\mathrm{S}_{0}\right)$ to obtain information about the nature of the singlet excited states $\left(S_{n}\right)$ involved in the absorption spectra. Calculations assign the lowintensity band above $300 \mathrm{~nm}$ (Figure 5 ) to the $S_{0} \rightarrow S_{1}$ electronic transition calculated around 3.4-3.7 eV for SPSO1-3 and SPSX
(Table S1 in the Supporting Information). This transition has a charge transfer (CT) nature since it implies an electron promotion from the HOMO, located on the non-functionalized fluorene, to the LUMO, spreading over the functionalized fluorene (Figure 6). The CT character of the transition explains the low intensity of the absorption band. The more intense band observed between 250 and $300 \mathrm{~nm}$ involves excitations to several excited singlets calculated in the 4.0-4.5 eV range with high oscillator strengths ( $f>0.1$, Table $\mathrm{S} 1$ ). These transitions mainly imply $\pi \rightarrow \pi^{*}$ excitations within the spirofluorene core.

To obtain an estimation of the emission energies, the geometry of the first singlet excited state was fully relaxed using the TD-DFT method. According to the calculations, emission takes place from the charge transfer $S_{1}$ state resulting from the HOMO $\rightarrow$ LUMO excitation for all the hosts. The emission energies follow the trend expected from the HOMO-LUMO gaps, with the value calculated for SPSO1 $(2.77 \mathrm{eV}, 448 \mathrm{~nm})$ slightly red shifted compared with SPSO2 $(2.84 \mathrm{eV}, 437 \mathrm{~nm})$ and SPSO3 $(2.83 \mathrm{eV}, 438 \mathrm{~nm})$ in excellent agreement with the emission maxima measured experimentally (432, 421, and 422 $\mathrm{nm}$, respectively, Table 2). For SPSX (2.96 eV, $419 \mathrm{~nm})$, calculations reproduce the shift to bluer wavelengths observed experimentally (Figure 5), although the predicted shift with respect to SPSO1 $(29 \mathrm{~nm})$ underestimates the experimental value $(52 \mathrm{~nm})$.

\begin{tabular}{|c|c|c|}
\hline Host & $E\left(\mathrm{~S}_{0} \rightarrow \mathrm{T}_{1}\right)$ & $\Delta E\left(\mathrm{~T}_{1}-\mathrm{S}_{0}\right)$ \\
\hline SP & 3.05 & 2.98 \\
\hline SPSO1 & 2.86 & 2.77 \\
\hline SPSO2 & 2.88 & 2.78 \\
\hline SPSO3 & 2.92 & 2.83 \\
\hline SPSX & 2.90 & 2.80 \\
\hline SPPO13 & 2.90 & 2.81 \\
\hline Flrpic & 2.83 & 2.73 \\
\hline
\end{tabular}

The nature of the lowest-energy triplet excited state $\left(T_{1}\right)$ was first investigated by performing a TD-DFT study at the optimized geometry of $\mathrm{S}_{0}$. For all the hosts, TD-DFT calculations predict that $\mathrm{T}_{1}$ mainly results from the HOMO-1 $\rightarrow$ LUMO excitation, which mostly concerns the functionalized fluorene moiety (see Figure 6 for SPSO1), and that the triplet state associated to the charge transfer HOMO $\rightarrow$ LUMO promotion appears higher in energy (Table $\mathrm{S} 2$ in the Supporting Information). The vertical excitation energies calculated at the TD-DFT level from $S_{0}$ to $T_{1}$ $\left(E\left(S_{0} \rightarrow T_{1}\right)\right)$ are similar for all the hosts and are given in Table 4 . In a second step, the geometry of the lowest-energy triplet was fully optimized using the spin-unrestricted UB3LYP approach. 
After full-geometry relaxation, the unpaired-electron spin density computed for $T_{1}$ shows the same distribution for all the hosts, including the phosphine oxide compound SPPO13, and is mainly confined on the functionalized fluorene moiety as depicted in Figure 8 for SPSO1. This confirms the electronic nature predicted for $T_{1}$ by TD-DFT calculations. The adiabatic energy of $T_{1}$ (computed as the difference in the DFT energies of $\mathrm{S}_{0}$ and $\mathrm{T}_{1}$ at their respective optimized geometries, $\left.\Delta E\left(\mathrm{~T}_{1}-\mathrm{S}_{0}\right)\right)$ is nearly identical for all the hosts, being between $2.77 \mathrm{eV}$ for SPSO1 and $2.83 \mathrm{eV}$ for SPSO3. The energy calculated for $T_{1}$ in SPP013 $(2.81 \mathrm{eV})$ is intermediate between these two values and is in very good accord with the experimental value of 2.73 $\mathrm{eV}$ obtained from low-temperature photoluminescence measurements. ${ }^{[4 a]}$ Calculations therefore show that although the introduction of sulfone groups significantly reduces the energy of the LUMO and leads to better electron acceptors compared to SPPO13, as discussed above, it mainly preserves the energy of the $T_{1}$ triplet. The adiabatic $T_{1}$ energies estimated for all the hosts are indeed higher than the value of $2.73 \mathrm{eV}$ calculated for FIrpic (experimental value of $2.65 \mathrm{eV}$ ). This suggests that the sulfone SPSO1-3 and sulfoxide SPSX systems can be used as effective hosts with the FIrpic phosphor as blue dopant.

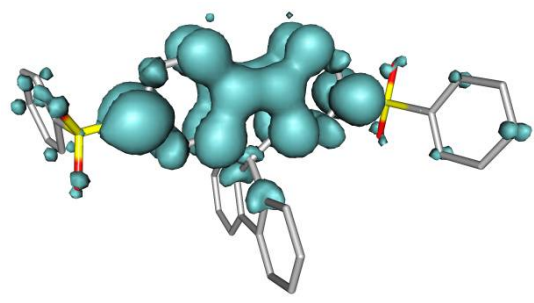

Figure 8. Unpaired-electron spin density contours (0.002 a.u.) calculated for the fully-relaxed $T_{1}$ triplet state of SPSO1.

Electroluminescent devices: The main advantages of LECs over OLEDs are their simple structure (consisting of a single active layer processed from solution) and their insensitivity to the work function of the electrodes employed. ${ }^{[19]}$ However, attempts to fabricate blue phosphorescent LECs (electroluminescence emission below $480 \mathrm{~nm}$ ) based on ionic transition-metal complexes remain extremely challenging due to self-quenching of the active material and unbalanced carrier transport in the emissive layer. Due to these factors, a maximum luminance of $94 \mathrm{~cd} \mathrm{~m}^{-2}$ (maximum efficacy of $4.3 \mathrm{~cd} \mathrm{~A}^{-1}$ ) was reported for blue iridium phosphors. ${ }^{[20]}$ Furthermore, light-emitting devices that use $100 \%$ rare-earth-based materials are not economically viable. The host-guest approach is an alternative that promises cheaper, more stable, and brighter LEC devices. ${ }^{[6,21]}$

We have tested the solution-processable SPSO1-3 hosts as electron transporters in blue host-guest LEC devices using Flrpic as the blue dopant and a previously synthesized ionic hole-transporting material NMS25 (see Scheme S1 in the Supporting Information for the molecular structure).$^{[6]}$ Solubility tests for the sulfone-host series are given in Table S3 in the Supporting Information. The performances of the blue host- guest LECs are illustrated in Figure 9 and are summarized in Table 5.
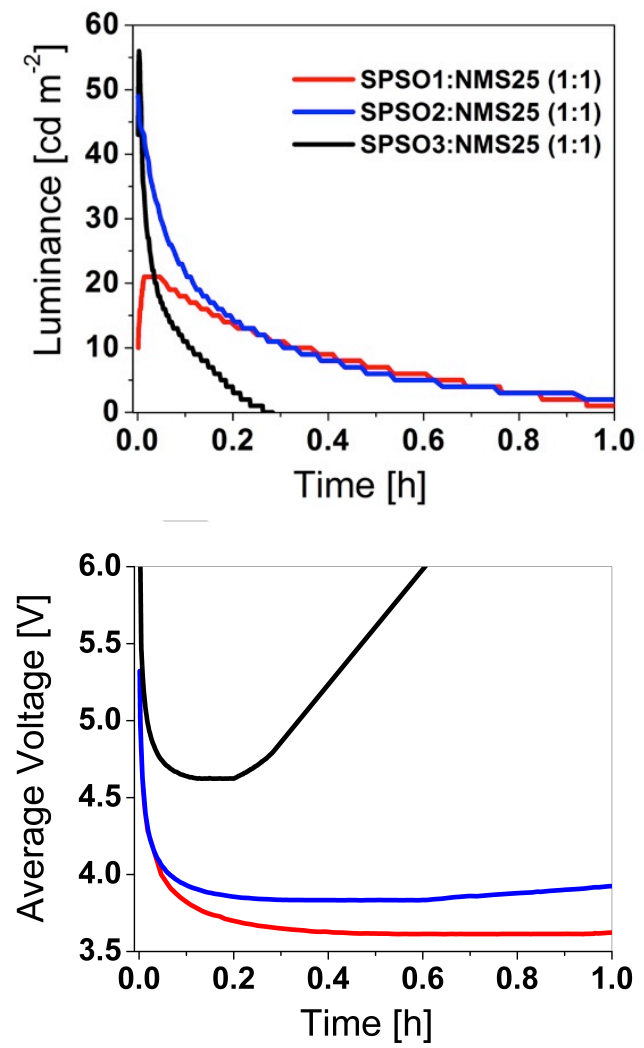

Figure 9. Luminance and average voltage vs. time of LEC devices with the acceptor hosts.

In Figure 9, we observe a drop in the driving voltage of $1.0 \mathrm{~V}$ in LEC $1(3.6 \mathrm{~V})$ when using the host SPSO1 compared to LEC $3(4.6 \mathrm{~V})$ with the host SPSO3 (Table 5). The lowered operating voltage may be attributed to the strong polarization effect ${ }^{[5 a]}$ of the aryl-sulfone group in SPSO1 forming a dipole layer at the AIcathode ${ }^{[5 b]}$ lowering the electron injection barrier. It can be speculated that the highly flexible alkyl-chains in SPSO3 effectively hinders the interaction of the sulfone-group with the Al-cathode. A low operating voltage of $3.8 \mathrm{~V}$ was observed with the host SPSO2 (LEC 2), bearing rigid mesityl groups. From the $X$-ray structures (Figure 1), it is obvious that the steric vicinity of the sulfone groups in SPSO2 is very similar to that in SPSO1. The lifetimes of LECs 1 and 2 with host SPSO1 and SPSO2, respectively, are significantly longer than that of LEC 3 (Table $5)$.

However, the performance of the LECs with the bis-n-alkylsulfone host, SPSO3, was considerably improved when the ratio SPSO3:NMS25 was increased in LEC 4 (Figure 10 and Table $5)$. This results in a doubling of the brightness and efficacy (123

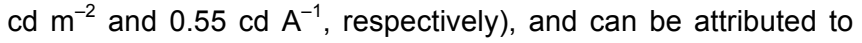
an improved balance of the hole and electron charge carriers within the emissive layer. ${ }^{[1 a, 6,21]}$ Moreover, the lifetime of the SPSO3 LEC was increased 14 times in LEC 5 when using the 
lipophilic ionic liquid (IL) $\left[\mathrm{THA}^{+}\left[\mathrm{BF}_{4}\right]^{-}\left([\mathrm{THA}]^{+}=\right.\right.$tetra- $n$-hexyl ammonium) and the non-ionic hole transporting material TCTA (see Figure 10 and Scheme 1 in the Supporting Information for the chemical structure of TCTA). This improvement in lifetime can be attributed to the better compatibility of the IL and the acceptor host SPSO3 resulting in increased stability of the emissive thin film. At the same time, the turn-on time in LEC 5 is increased. This trend of increase in turn-on time leading to an increase in lifetime is often observed in LECs and is due to the role of ionic motion in these devices. In LEC 5 using lipophilic ions, the mobility is reduced explaining the observed results in lifetime and turn-on time.

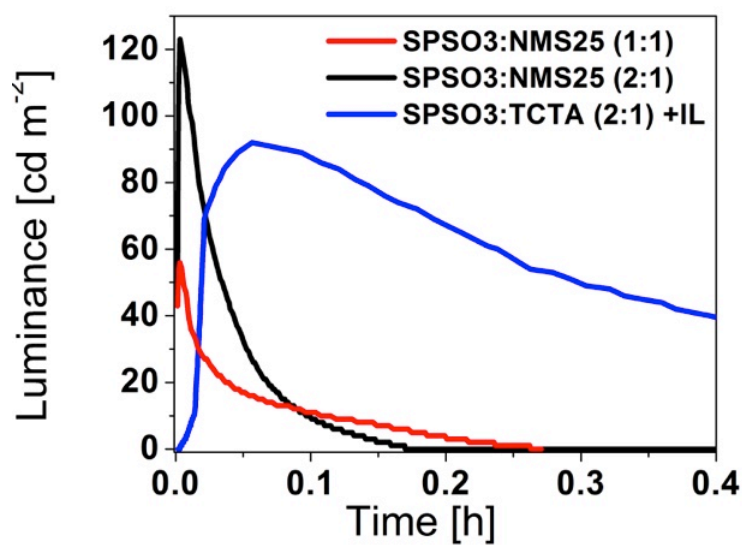

Figure 10. Luminance vs. time of LEC devices with SPSO3.

No working LEC device was obtained with the host SPSX which may be related to a decomposition reaction at the Al-cathode. However, it is demonstrated that all members of the sulfoneacceptor host series give working blue-phosphorescent LECs.

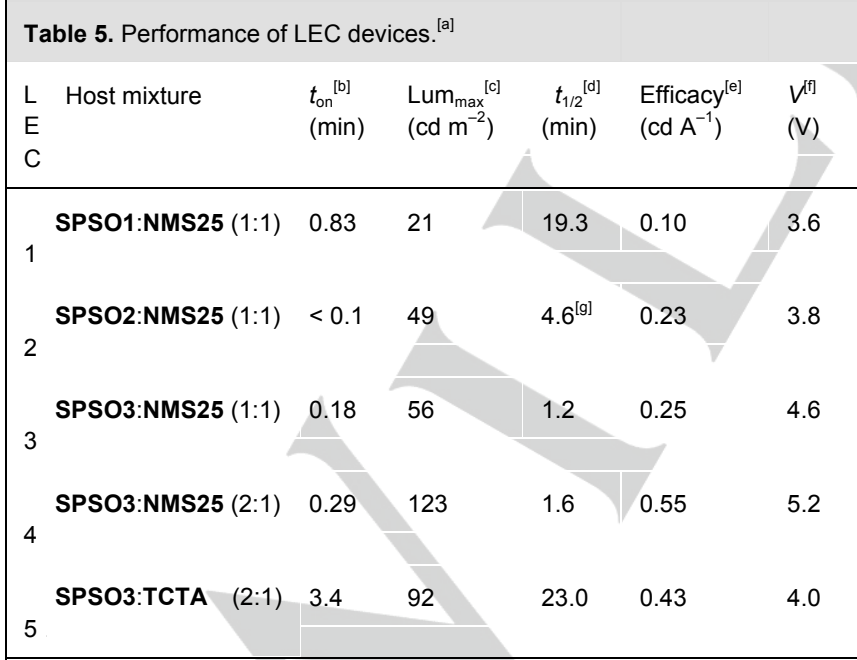

[a] FIrpic was $10 \%$ in all LEC devices. [b] The turn-on time $\left(t_{\text {on }}\right)$ is the time to reach the maximum luminance. [c] Maximum luminance. [d] The lifetime $\left(t_{1 / 2}\right)$ is the time to reach half of maximum luminance. [e] Maximum efficacy. [f] Operating average voltage. [g] Lower lifetime mainly due to higher luminance, not an indication of lower stability.

\section{Conclusions}

Four electron-acceptor hosts SPSO1, SPSO2, SPSO3, and SPSX containing sulfone- or sulfoxide-functionalized spirobifluorenes have been prepared and characterized. The single crystal structures of SPSO1, SPSO2 and SPSO3 have been determined. Trends in the electrochemical behaviour of the compounds are consistent with the electron-withdrawing properties of the sulfone or sulfoxide groups. The emission maxima of all four hosts lie in the range 421-432 nm, which overlaps with the MLCT absorption of the sky-blue emitter FIrpic, and thus leads to energy transfer from the acceptor hosts to FIrpic. Theoretical calculations show that although the introduction of sulfone groups significantly reduces the energy of the LUMO and leads to better electron acceptors compared to analogous phosphine oxide functionalized hosts, it does not affect the energy of the lowest lying triplet $(\sim 2.80 \mathrm{eV})$ which is maintained above the triplet of Flrpic. The acceptor hosts have been tested in LEC devices. LECs containing the sulfone hosts SPSO1 and SPSO2 (aryl sulfones) perform better than those with SPSO3 (long chain alkyl sulfone substituents); no working LEC was obtained with the sulfoxide-functionalized host material.

The study has revealed a promising class of acceptor hosts for use in LECs. The synthetic route used to prepare SPSO1, SPSO2 and SPSO3 can be readily adapted using the pool of commercially available aryl- and alkyl-thiols, functionalized with ethers, alcohols, esters, and carboxylic acids to obtain a wide range of polar acceptor-hosts with tailor-made solubility properties required for solution-based materials deposition.

\section{Experimental Section}

General: All of the starting materials were commercially available, of reagent grade, and used without further purification. The solvents were reagent grade or distilled, except for the $p$-xylene which was dried by refluxing over $\mathrm{NaH}$. Column chromatography was performed using Fluka silica gel $60(40-63 \mu \mathrm{m})$, Silicycle SilicaFlash P60 $(40-63 \mu \mathrm{m}) .{ }^{1} \mathrm{H}$ and ${ }^{13} \mathrm{C}\left\{{ }^{1} \mathrm{H}\right\}$ NMR spectra were recorded on a Bruker DRX400 $(400 \mathrm{MHz})$ or on a Bruker DRX500 (500 MHz) spectrometer at $295 \mathrm{~K}$. The chemical shifts were referenced with respect to residual solvent peaks with $\delta$ $(\mathrm{TMS})=0$. IR spectra were recorded on a Shimadzu FTIR-8400S spectrophotometer using neat samples and a Golden Gate attachment for solid state samples. El mass spectra were recorded on a Finnigan MAT 95Q spectrometer. MALDI-TOF mass spectrometry was done using a Voyager-DE PRO spectrometer. Measurement of UV-Vis spectra was carried out on an Agilent Technologies UV-Visible 8453 spectrophotometer and a Shimadzu RF-5301PC spectrofluorometer was used to measure the photoluminescence spectra. Cyclic voltammetry was recorded on a $\mathrm{CH}$ Instruments $900 \mathrm{~B}$ potentiostat with glassy carbon working and platinum auxiliary electrodes; a silver wire was used as a pseudo-reference electrode and ferrocene as internal reference.

The syntheses of compounds 4 and $\mathbf{5}$, and alternative syntheses of SPSO1 and SPSX are given in the Supporting Information. See Supporting Information for the atom labelling for NMR assignments.

2,7-Bis(phenylthio)-9,9'-spirobifluorene (1): Method a: A dried flask was charged with 2,7-dibromo-9,9'-spirobifluorene $(371 \mathrm{mg}, 0.782 \mathrm{mmol}$, 
1.00 eq.), $\mathrm{K}_{2} \mathrm{CO}_{3}$ (554 mg, $4.01 \mathrm{mmol}, 5.12$ eq.), and thiophenol $(0.82 \mathrm{~mL}$, $884 \mathrm{mg}, 8.02 \mathrm{mmol}, 10.3$ eq.) under an argon atmosphere. Dry DMF $(4 \mathrm{~mL})$ was added and the suspension was stirred for $22 \mathrm{~h}$ at $140^{\circ} \mathrm{C}$. $\mathrm{CH}_{2} \mathrm{Cl}_{2}$ was added to the mixture and the precipitate was filtered off. The filtrate was washed with $\mathrm{H}_{2} \mathrm{O}$, the aqueous layer was extracted with $\mathrm{CH}_{2} \mathrm{Cl}_{2}$ and the combined organic layers were washed three times with $\mathrm{H}_{2} \mathrm{O}$ and dried over $\mathrm{Na}_{2} \mathrm{SO}_{4}$. The solvent was removed under reduced pressure. Cyclohexane was added to the residue and the suspension was heated until everything had dissolved. The precipitate was filtered, washed with cyclohexane, dissolved with $\mathrm{CHCl}_{3}$, and the solvent was removed under reduced pressure. The residue was recrystallized from cyclohexane and dried under vacuum, the filtrate was concentrated under reduced pressure and the residue was again recrystallized from cyclohexane and dried under vacuum. From both recrystallizations, the product 1 was obtained as colourless crystals. Yield: $320 \mathrm{mg}, 0.60 \mathrm{mmol}$, $77 \% .{ }^{1} \mathrm{H}$ NMR $\left(500 \mathrm{MHz}, \mathrm{CD}_{2} \mathrm{Cl}_{2}\right): \delta / \mathrm{ppm}=7.84$ (pseudo-dt, ${ }^{3} \mathrm{~J}(\mathrm{H}, \mathrm{H})=$ $\left.7.8 \mathrm{~Hz},{ }^{4,5} \mathrm{~J}(\mathrm{H}, \mathrm{H})=0.9 \mathrm{~Hz}, 2 \mathrm{H} ; \mathrm{H}^{\prime}, 5^{\prime}\right), 7.77\left(\mathrm{dd},{ }^{3} \mathrm{~J}(\mathrm{H}, \mathrm{H})=8.1 \mathrm{~Hz}\right.$, $\left.{ }^{5} \mathrm{~J}(\mathrm{H}, \mathrm{H})=0.6 \mathrm{~Hz}, 2 \mathrm{H} ; \mathrm{H} 4,5\right), 7.39$ (pseudo-td, ${ }^{3} \mathrm{~J}(\mathrm{H}, \mathrm{H})=7.6 \mathrm{~Hz},{ }^{4} \mathrm{~J}(\mathrm{H}, \mathrm{H})$ $\left.=1.1 \mathrm{~Hz}, 2 \mathrm{H} ; \mathrm{H}^{\prime}, 6^{\prime}\right), 7.29\left(\mathrm{dd},{ }^{3} \mathrm{~J}(\mathrm{H}, \mathrm{H})=8.1 \mathrm{~Hz},{ }^{4} \mathrm{~J}(\mathrm{H}, \mathrm{H})=1.7 \mathrm{~Hz}, 2 \mathrm{H}\right.$; $\mathrm{H} 3,6), 7.23$ - $7.14\left(\mathrm{~m}, 12 \mathrm{H} ; \mathrm{H}^{\prime}, 7^{\prime}, \mathrm{SPh}-\mathrm{H} 2,4\right), 6.77-6.75(\mathrm{~m}, 4 \mathrm{H}$; $\left.\mathrm{H} 1,8,1^{\prime}, 8^{\prime}\right) .{ }^{13} \mathrm{C}\left\{{ }^{1} \mathrm{H}\right\}$ NMR (126 MHz, $\left.\mathrm{CD}_{2} \mathrm{Cl}_{2}\right): \delta / \mathrm{ppm}=150.54(\mathrm{C} 2,7)$, 148.25 (C8'a,9'a), 142.33 (C4'a,4'b), 140.94 (C4a,4b), 136.53 (SPh-C1), 135.56 (C8a,9a), 131.54 (C3,6), 130.70 (SPh-C2/C3), 129.62 (SPhC2/C3), 128.59 (C3',6'), 128.44 (C2',7'), 127.42 (C1,8/SPh-C4), 127.36 (C1,8/SPh-C4), 124.27 (C1',8'), 121.46 (C4,5), 120.79 (C4',5'), 66.21 (C9). IR (solid): v/cm ${ }^{-1}=3062(\mathrm{w}), 1573(\mathrm{w}), 1472(\mathrm{~m}), 1446(\mathrm{~m}), 1439$ (s), $1399(\mathrm{~m}), 1252(\mathrm{w}), 1179(\mathrm{w}), 1154(\mathrm{w}), 1070(\mathrm{~m}), 1024(\mathrm{~m}), 1000$ (w), 959 (w), $920(\mathrm{w}), 860$ (m), 809 (s), 763 (s), 751 (s), 744 (s), 733 (s), 723 (s), 704 (s), 692 (s), 684 (s), 679 (m), 673 (s). UV/Vis (MeCN, $1.0 \times 10^{-5} \mathrm{~mol} \mathrm{dm}^{-3}$,): $\lambda_{\max }(\varepsilon)=220$ (sh, 82000), 270 (sh, 37000), 334 $\mathrm{nm}\left(29000 \mathrm{dm}^{3} \mathrm{~cm}^{-1} \mathrm{~mol}^{-1}\right)$. Fluorescence (MeCN, $1.0 \times 10^{-5} \mathrm{~mol} \mathrm{dm}^{-3}$, $\left.\lambda_{\mathrm{ex}}=320 \mathrm{~nm}\right): \lambda_{\mathrm{em}}=374 \mathrm{~nm}$. MS $(\mathrm{El}, 70 \mathrm{eV}): \mathrm{m} / \mathrm{z}(\%)=532.1[\mathrm{M}]^{+}(100$, calcd. 532.1). See the Supporting Information for Methods $b$ and $c$.

2,7-Bis(phenylsulfinyl)-9,9'-spirobifluorene (SPSX): Oxidation with $\mathrm{H}_{2} \mathrm{O}_{2}$ : $0.57 \mathrm{~mL}$ of a $0.89 \mathrm{M} \mathrm{H}_{2} \mathrm{O}_{2}(0.508 \mathrm{mmol}, 2.0$ eq.) solution in $\mathrm{AcOH}$ $(100 \%)$ were added to a solution of 2,7-bis(phenylthio)-9,9'spirobifluorene $(1,135 \mathrm{mg}, 0.254 \mathrm{mmol}, 1.00$ eq.) in a $1: 1$ mixture of $\mathrm{CHCl}_{3}$ and $\mathrm{AcOH}(3 \mathrm{~mL})$ at $0^{\circ} \mathrm{C}$. The solution was stirred for $30 \mathrm{~h}$ at room temperature, poured onto $\mathrm{H}_{2} \mathrm{O}$ and extracted with $\mathrm{CH}_{2} \mathrm{Cl}_{2}$. The combined organic layers were washed with $\mathrm{H}_{2} \mathrm{O}$ until no peroxide was present any more, dried over $\mathrm{Na}_{2} \mathrm{SO}_{4}$, and the solvent was removed under reduced pressure. The residue was purified by column chromatography $\left(\mathrm{SiO}_{2}\right.$; cyclohexane:EtOAc 9:1 $\rightarrow$ 1:1) and dried under vacuum to yield SPSX as a colourless powder. Yield: $0.10 \mathrm{~g}, 0.18 \mathrm{mmol}, 70 \% .{ }^{1} \mathrm{H}$ and ${ }^{13} \mathrm{C}$ NMR signals of the two diastereomers are marked with and without an asterisk: ${ }^{1} \mathrm{H}$ NMR $\left(500 \mathrm{MHz}, \mathrm{CDCl}_{3}\right): \delta / \mathrm{ppm}=7.88-7.85(\mathrm{~m}, 4 \mathrm{H}$; $\left.\mathrm{H} 4,5,4^{*}, 5^{*}, 4^{\prime}, 5^{\prime}, 4^{\prime *}, 5^{\prime *}\right), 7.54-7.51\left(\mathrm{~m}, 2 \mathrm{H} ; \mathrm{H} 3,6,3^{*}, 6^{*}\right), 7.48-7.44(\mathrm{~m}$ $\left.4 \mathrm{H} ; \mathrm{S}(\mathrm{O}) \mathrm{Ph}-\mathrm{H} 2,2^{*}\right), 7.44-7.34\left(\mathrm{~m}, 8 \mathrm{H} ; \mathrm{H}^{\prime}, 6^{\prime}, 3^{\prime *}, 6^{\prime *}, \mathrm{~S}(\mathrm{O}) \mathrm{Ph}-\mathrm{H} 3,4,3^{*}, 4^{*}\right)$, $7.15-7.14\left(\mathrm{~m}, 2 \mathrm{H} ; \mathrm{H} 1,8,1^{*}, 8^{*}\right), 7.12-7.05$ (m, 2H; H2',7',2** $\left.7^{\prime *}\right), 6.61$ $6.57\left(\mathrm{~m}, 2 \mathrm{H} ; \mathrm{H} 1^{\prime}, 8^{\prime}, 1^{\prime *}, 8^{* *}\right) .{ }^{13} \mathrm{C}\left\{\left\{^{1} \mathrm{H}\right\}\right.$ NMR (101 $\left.\mathrm{MHz} \mathrm{CDCl}_{3}\right): \delta / \mathrm{ppm}=$

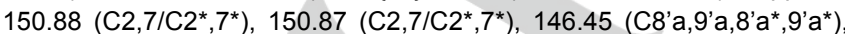
146.19 (C8a,9a,8a*,9a*), 145.52 (S(O)Ph-C1/C1*), 145.51 (S(O)PhC1/C1*), $143.31\left(C 4 a, 4 b / C 4 a^{*}, 4 b^{*}\right), 143.30\left(C 4 a, 4 b / C 4 a^{*}, 4 b^{*}\right), 142.14$ (C4'a,4'b/ C4'a*,4'b*), 142.13 (C4'a,4'b/C4'a*,4'b*), 131.192 (S(O)Ph$\left.\mathrm{C} 4 / \mathrm{C}^{*}\right), \quad 131.186 \quad\left(\mathrm{~S}(\mathrm{O}) \mathrm{Ph}-\mathrm{C} 4 / \mathrm{C} 4^{*}\right), \quad 129.41 \quad(\mathrm{~S}(\mathrm{O}) \mathrm{Ph}-\mathrm{C} 3), \quad 128.61$

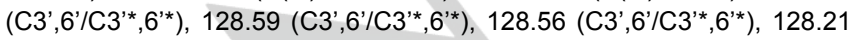
$\left(\mathrm{C} 2^{\prime}, 7^{\prime} / \mathrm{C} 2^{\prime *}, 7^{\prime *}\right), 128.18\left(\mathrm{C}^{\prime}, 7^{\prime} / \mathrm{C} 2^{\prime *}, 7^{\prime *}\right), 128.15$ (C2',7'/ C2,*, $\left.7^{\prime *}\right), 124.98$ (S(O)Ph-C2/C2*), $124.97\left(\mathrm{~S}(\mathrm{O}) \mathrm{Ph}-\mathrm{C} 2 / \mathrm{C} 2^{*}\right), 124.87\left(\mathrm{C} 3,6,3^{*}, 6^{*}\right), 123.94$ $\left(\mathrm{C} 1^{\prime}, 8^{\prime} / \mathrm{C} 1^{\prime *}, 8^{\prime *}\right), 123.91\left(\mathrm{C} 1^{\prime}, 8^{\prime} / \mathrm{C} 1^{\prime *}, 8^{\prime *}\right), 123.86\left(\mathrm{C} 1^{\prime}, 8^{\prime} / \mathrm{C} 1^{\prime *}, 8^{\prime *}\right), 121.56$ $\left(\mathrm{C} 4,5 / \mathrm{C} 4^{*}, 5^{*}\right), \quad 121.54\left(\mathrm{C} 4,5 / \mathrm{C} 4^{*}, 5^{*}\right), \quad 121.27 \quad\left(\mathrm{C} 1,8 / \mathrm{C} 1^{*}, 8^{*}\right), \quad 121.23$ $\left(\mathrm{C} 1,8 / \mathrm{C}^{*}, 8^{*}\right), 120.64\left(\mathrm{C} 4^{\prime}, 5^{\prime}, 4^{* *}, 5^{\prime *}\right), 66.13\left(\mathrm{C} 9,9^{*}\right)$. IR (solid): $\mathrm{v} / \mathrm{cm}^{-1}=$ $3056(w), 2925(w), 1474(m), 1442(m), 1398(m), 1082(s), 1070(m)$, $1040(\mathrm{~s}), 1020(\mathrm{~m}), 1002(\mathrm{~m}), 997(\mathrm{~m}), 818(\mathrm{~m}), 761$ (s), $744(\mathrm{~s}), 734(\mathrm{~s})$,
726 (s), 686 (s), 636 (s). UV/Vis (MeCN, $\left.1.0 \times 10^{-5} \mathrm{~mol} \mathrm{dm}^{-3}\right): \lambda_{\max }(\varepsilon)=$

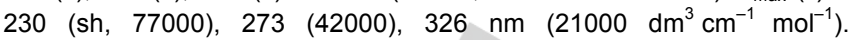
Fluorescence $\left(\mathrm{MeCN}, 1.0 \times 10^{-5} \mathrm{~mol} \mathrm{dm}^{-3}, \lambda_{\mathrm{ex}}=300 \mathrm{~nm}\right): \lambda_{\mathrm{em}}=380 \mathrm{~nm}$ MS (El, $70 \mathrm{eV}): m / z(\%)=564.1\left[\mathrm{M}^{+}(100\right.$, calcd. 564.1). Anal. calcd. for $\mathrm{C}_{37} \mathrm{H}_{24} \mathrm{O}_{2} \mathrm{~S}_{2}$ : C 78.70, $\mathrm{H} 4.28$; found: C 78.52, $\mathrm{H} 4.58$.

2,7-Bis(phenylsulfonyl)-9,9'-spirobifluorene (SPSO1): Oxidation at elevated temperature: $15 \mathrm{~mL}$ of a $0.89 \mathrm{M} \mathrm{H}_{2} \mathrm{O}_{2}$ (13.4 mmol, 7.13 eq.) solution in $\mathrm{AcOH}(100 \%)$ were added to a solution of 2,7-bis(phenylthio)9,9'-spirobifluorene (1, $1.00 \mathrm{~g}, 1.88 \mathrm{mmol}, 1.00$ eq.) in $\mathrm{CHCl}_{3}(15 \mathrm{~mL})$ at $0^{\circ} \mathrm{C}$. The solution was stirred for $1 \mathrm{~h}$ at room temperature, heated to reflux for $2 \mathrm{~h}$, then stirred at room temperature overnight, heated to reflux again for $1.5 \mathrm{~h}$, and cooled to room temperature. The solution was poured onto $\mathrm{H}_{2} \mathrm{O}$ and extracted with $\mathrm{CH}_{2} \mathrm{Cl}_{2}$. The combined organic layers were washed with $\mathrm{H}_{2} \mathrm{O}$ until no peroxide was present any more, dried over $\mathrm{Na}_{2} \mathrm{SO}_{4}$, and the solvent was removed under reduced pressure. The residue was purified by column chromatography $\left(\mathrm{SiO}_{2}\right.$; cyclohexane:EtOAc 1:1), recrystallized from 1,4-dioxane, and dried under vacuum to yield the SPSO1 as colourless crystals. Yield: $1.0 \mathrm{~g}, 1.7 \mathrm{mmol}$, $89 \% . \quad{ }^{1} \mathrm{HNMR} \quad\left(500 \mathrm{MHz}, \mathrm{CDCl}_{3}\right): \delta / \mathrm{ppm}=7.95-7.88 \quad(\mathrm{~m}, \quad 6 \mathrm{H}$; $\left.\mathrm{H} 3,4,5,6,4^{\prime}, 5^{\prime}\right), 7.78-7.76\left(\mathrm{~m}, 4 \mathrm{H} ; \mathrm{SO}_{2} \mathrm{Ph}-\mathrm{H} 2\right), 7.51\left(\mathrm{tt},{ }^{3} \mathrm{~J}(\mathrm{H}, \mathrm{H})=7.5 \mathrm{~Hz}\right.$, $\left.{ }^{4} \mathrm{~J}(\mathrm{H}, \mathrm{H})=1.2 \mathrm{~Hz}, 2 \mathrm{H} ; \mathrm{SO}_{2} \mathrm{Ph}-\mathrm{H} 4\right), 7.45-7.40\left(\mathrm{~m}, 8 \mathrm{H} ; \mathrm{H} 1,8,3\right.$ ',6', $\mathrm{SO}_{2} \mathrm{Ph}-$ $\mathrm{H} 3$ ), 7.08 (pseudo-td, ${ }^{3} \mathrm{~J}(\mathrm{H}, \mathrm{H})=7.5 \mathrm{~Hz},{ }^{4} \mathrm{~J}(\mathrm{H}, \mathrm{H})=1.1 \mathrm{~Hz}, 2 \mathrm{H} ; \mathrm{H2}{ }^{\prime}, 7^{\prime}$ ), 6.54 (pseudo-dt, ${ }^{3} J(\mathrm{H}, \mathrm{H})=7.6 \mathrm{~Hz},{ }^{4} J(\mathrm{H}, \mathrm{H})=0.9,{ }^{5} \mathrm{~J}(\mathrm{H}, \mathrm{H})=0.6 \mathrm{~Hz}, 2 \mathrm{H}$; $\left.\mathrm{H} 1^{\prime}, 8^{\prime}\right) .{ }^{13} \mathrm{C}\left\{{ }^{1} \mathrm{H}\right\}$ NMR $\left(126 \mathrm{MHz}, \mathrm{CDCl}_{3}\right): \delta / p p m=151.40(\mathrm{C} 2,7), 145.44$

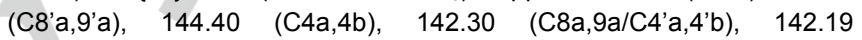
(C8a,9a/C4'a,4'b), $141.40 \quad\left(\mathrm{SO}_{2} \mathrm{Ph}-\mathrm{C} 1\right), 133.36 \quad\left(\mathrm{SO}_{2} \mathrm{Ph}-\mathrm{C} 4\right), 129.39$ ( $\mathrm{SO}_{2} \mathrm{Ph}-\mathrm{C} 3$ ), 128.88 (C3',6'), 128.36 (C3,6/C2',7'), 128.34 (C3,6/C2',7'), $127.68\left(\mathrm{SO}_{2} \mathrm{Ph}-\mathrm{C} 2\right), 123.87$ (C1',8'), 123.77 (C1,8), 121.84 (C4,5), 120.85 (C4',5'), 66.18 (C9). IR (solid): $v / \mathrm{cm}^{-1}=3069(\mathrm{w}), 1446(\mathrm{~m})$, $1402(w), 1314(\mathrm{~m}), 1306(\mathrm{~s}), 1177(\mathrm{w}), 1145(\mathrm{~s}), 1089(\mathrm{~s}), 1063(\mathrm{w})$, $1004(\mathrm{~m}), 935(\mathrm{w}), 821(\mathrm{~m}), 769$ (s), 750 (s), 721 (s), 691 (s), 682 (s). UV/Vis (MeCN, $1.0 \times 10^{-5} \mathrm{~mol} \mathrm{dm}^{-3}$,): $\lambda_{\max }(\varepsilon)=227$ (sh, 60400), 260 (sh, 33400), 286 (42600), 299 (41300), $323 \mathrm{~nm}\left(13400 \mathrm{dm}^{3} \mathrm{~cm}^{-1} \mathrm{~mol}^{-1}\right)$. Fluorescence $\left(\mathrm{MeCN}, 1.0 \times 10^{-5} \mathrm{~mol} \mathrm{dm}^{-3}, \lambda_{\mathrm{ex}}=297 \mathrm{~nm}\right): \lambda_{\mathrm{em}}=432 \mathrm{~nm}$. MS (El, $70 \mathrm{eV}): m / z(\%)=596.1[\mathrm{M}]^{+}(100$, calcd. 596.1). Anal. calcd. for $\mathrm{C}_{37} \mathrm{H}_{24} \mathrm{O}_{4} \mathrm{~S}_{2}$ : C 74.48, H 4.05; found: C 74.13, H 4.05.

2,7-Bis(mesitylthio)-9,9'-spirobifluorene (2): A dried flask was charged with 2,7-dibromo-9,9'-spirobifluorene (1), $400 \mathrm{mg}, 0.844 \mathrm{mmol}, 1.00$ eq.), $\mathrm{K}_{2} \mathrm{CO}_{3}$ (587 mg, $4.25 \mathrm{mmol}, 5.03$ eq.), and 2,4,6-trimethylthiophenol (0.38 mL, $2.52 \mathrm{mmol}, 2.99$ eq.) under an argon atmosphere. Dry DMF $(4 \mathrm{~mL})$ was added and the suspension was stirred for $18 \mathrm{~h}$ at $140^{\circ} \mathrm{C}$. More 2,4,6-trimethylthiophenol $(0.25 \mathrm{~mL}, 1.66 \mathrm{mmol}, 1.97$ eq. $)$, more $\mathrm{K}_{2} \mathrm{CO}_{3}$ (485 mg, $3.51 \mathrm{mmol}, 4.16$ eq.), and more dry DMF (2 mL) were added and the mixture was stirred for $4 \mathrm{~d}$ at $140^{\circ} \mathrm{C}$. The mixture was poured into $\mathrm{H}_{2} \mathrm{O}(100 \mathrm{~mL})$ and extracted with $\mathrm{CH}_{2} \mathrm{Cl}_{2}(4 \times 50 \mathrm{~mL})$. The combined organic layers were washed with $\mathrm{H}_{2} \mathrm{O}(3 \times 50 \mathrm{~mL})$ and dried over $\mathrm{Na}_{2} \mathrm{SO}_{4}$. The solvent was removed under reduced pressure and the residue was diluted with $\mathrm{CH}_{2} \mathrm{Cl}_{2}(100 \mathrm{~mL})$ and washed twice with $\mathrm{H}_{2} \mathrm{O}$. The organic layers were again dried over $\mathrm{Na}_{2} \mathrm{SO}_{4}$ and the solvent was removed under reduced pressure. The residue was again diluted, washed, and dried and the residue was then purified by column chromatography $\left(\mathrm{SiO}_{2}\right.$; cyclohexane: $\mathrm{CH}_{2} \mathrm{Cl}_{2}$ 1:0 $\rightarrow$ 9:1) and dried under vacuum. Yield: $255 \mathrm{mg}, 0.414 \mathrm{mmol}, 49 \% .{ }^{1} \mathrm{H}$ NMR $\left(500 \mathrm{MHz}^{-\mathrm{CDCl}_{3}}\right.$ ): $\delta / \mathrm{ppm}=7.82$ (pseudo-dt, ${ }^{3} \mathrm{~J}(\mathrm{H}, \mathrm{H})=7.5 \mathrm{~Hz},{ }^{4,5} \mathrm{~J}(\mathrm{H}, \mathrm{H})=0.9 \mathrm{~Hz}, 2 \mathrm{H}$; $\left.\mathrm{H}^{\prime}, 5^{\prime}\right), 7.43\left(\mathrm{dd},{ }^{3} \mathrm{~J}(\mathrm{H}, \mathrm{H})=7.7 \mathrm{~Hz},{ }^{5} \mathrm{~J}(\mathrm{H}, \mathrm{H})=1.1 \mathrm{~Hz}, 2 \mathrm{H} ; \mathrm{H} 4,5\right), 7.38$ (pseudo-td, $\left.{ }^{3} \mathrm{~J}(\mathrm{H}, \mathrm{H})=7.5 \mathrm{~Hz},{ }^{4} \mathrm{~J}(\mathrm{H}, \mathrm{H})=1.1 \mathrm{~Hz}, 2 \mathrm{H} ; \mathrm{H}^{\prime}, 6^{\prime}\right), 7.14$ (pseudo-td, $\left.{ }^{3} \mathrm{~J}(\mathrm{H}, \mathrm{H})=7.5 \mathrm{~Hz},{ }^{4} \mathrm{~J}(\mathrm{H}, \mathrm{H})=1.1 \mathrm{~Hz}, 2 \mathrm{H} ; \mathrm{H} 2^{\prime}, 7^{\prime}\right), 6.93(\mathrm{~s}, 4 \mathrm{H}$; SMes-H3,5), 6.75 (pseudo-dt, ${ }^{3} \mathrm{~J}(\mathrm{H}, \mathrm{H})=7.6 \mathrm{~Hz},{ }^{4,5} \mathrm{~J}(\mathrm{H}, \mathrm{H})=0.8 \mathrm{~Hz}, 2 \mathrm{H}$; H1', 8'), 6.57 - 6.54 (m, 4H; H1,3,6,8), 2.28 (s, 6H; SMes-C4-CH $\mathrm{H}_{3}$ ), 2.26 (s, 12H; SMes-C2,6-CH $\left.\mathrm{CH}_{3}\right) \cdot{ }^{13} \mathrm{C}\left\{{ }^{1} \mathrm{H}\right\}$ NMR (126 MHz, CDCl 3 ): $/ \mathrm{ppm}=$ 149.37 (C2,7), 148.59 (C8'a,9'a), 143.51 (SMes-C2,6), 141.81 (C4'a,4'b), 139.21 (SMes-C4), 138.49 (C4a,4b), 137.66 (C8a,9a), 129.38 (SMes- 
C3,5), 127.91 (C2',7'/C3',6'), 127.87 (C2',7'/C3',6'), 127.35 (SMes-C1), 124.47 (C3,6), 124.25 (C1', $\left.{ }^{\prime}\right), 122.27$ (C1,8), 120.12 (C4,5/C4',5), 120.08 (C4,5/C4',5'), 65.70 (C9), 21.83 (SMes-C2,6-CH ${ }_{3}$ ), 21.23 (SMesC4- $\mathrm{CH}_{3}$ ). IR (solid): $v / \mathrm{cm}^{-1}=2916(\mathrm{~m}), 2847(\mathrm{w}), 1597(\mathrm{~m}), 1566(\mathrm{w})$, $1443(\mathrm{~s}), 1404(\mathrm{~m}), 1373(\mathrm{w}), 1281(\mathrm{w}), 1250(\mathrm{w}), 1173(\mathrm{w}), 1157(\mathrm{w})$, $1057(\mathrm{~m}), 1034(\mathrm{w}), 957(\mathrm{w}), 849(\mathrm{~m}), 810(\mathrm{~s}), 764(\mathrm{~m}), 733(\mathrm{~s}), 687(\mathrm{~m})$, $640(\mathrm{~m})$. UV/Nis $\left(\mathrm{MeCN}, 1.0 \times 10^{-5} \mathrm{~mol} \mathrm{dm}^{-3}\right): \lambda_{\max }(\varepsilon)=225(\mathrm{sh}, 71000)$, $317(37000), 340 \mathrm{~nm}\left(34000 \mathrm{dm}^{3} \mathrm{~cm}^{-1} \mathrm{~mol}^{-1}\right)$. Fluorescence (MeCN, $\left.1.1 \times 10^{-5} \mathrm{~mol} \mathrm{dm}^{-3}, \lambda_{\mathrm{ex}}=320 \mathrm{~nm}\right): \lambda_{\mathrm{em}}=359 \mathrm{~nm}$. MS $(\mathrm{EI}, 70 \mathrm{eV}): \mathrm{m} / \mathrm{z}=$ $616.2[\mathrm{M}]^{+}\left(100\right.$, calcd. 616.2), $308.1[\mathrm{M}]^{2+}(8.6)$

\section{2,7-Bis(mesitylsulfonyl)-9,9'-spirobifluorene}

(SPSO2):

Bis(mesitylthio)-9,9'-spirobifluorene (2, $158 \mathrm{mg}, 0.256 \mathrm{mmol}, 1.00$ eq.) was dissolved in EtOAc $(20 \mathrm{~mL})$ and $\mathrm{AcOH}(100 \%, 5 \mathrm{~mL}) . \mathrm{H}_{2} \mathrm{O}_{2}(30 \%$, $0.250 \mathrm{~mL}, 352 \mathrm{mg}, 3.10 \mathrm{mmol}, 12.1 \mathrm{eq}$.) was added and the solution was heated to reflux for $18 \mathrm{~h}$. The solution was poured onto $\mathrm{H}_{2} \mathrm{O}$ and extracted with EtOAc. The combined organic layers were washed with $\mathrm{H}_{2} \mathrm{O}$ until no peroxide was present any more, dried over $\mathrm{Na}_{2} \mathrm{SO}_{4}$, and the solvent was removed under reduced pressure. The residue was recrystallised from a mixture of cyclohexane and toluene and dried under vacuum. Purification by column chromatography $\left(\mathrm{SiO}_{2}\right.$ cyclohexane:EtOAc 3:1) yielded SPSO2 as a colourless powder. Yield: $110 \mathrm{mg}, 0.26 \mathrm{mmol}, 63 \% .{ }^{1} \mathrm{H}$ NMR $\left(500 \mathrm{MHz}, \mathrm{CDCl}_{3}\right): \delta / \mathrm{ppm}=7.88(\mathrm{~d}$, $\left.{ }^{3} J(\mathrm{H}, \mathrm{H})=7.6 \mathrm{~Hz}, 2 \mathrm{H} ; \mathrm{H}^{\prime}, 5^{\prime}\right), 7.85\left(\mathrm{~d},{ }^{3} J(\mathrm{H}, \mathrm{H})=8.1 \mathrm{~Hz}, 2 \mathrm{H} ; \mathrm{H} 4,5\right), 7.59$ $\left(\mathrm{dd},{ }^{3} \mathrm{~J}(\mathrm{H}, \mathrm{H})=8.1 \mathrm{~Hz},{ }^{4} \mathrm{~J}(\mathrm{H}, \mathrm{H})=1.7 \mathrm{~Hz}, 2 \mathrm{H} ; \mathrm{H} 3,6\right), 7.43-7.40(\mathrm{~m}, 4 \mathrm{H}$; $\mathrm{H} 1,8,3^{\prime}, 6^{\prime}$ ), 7.10 (pseudo-td, ${ }^{3} J(\mathrm{H}, \mathrm{H})=7.6 \mathrm{~Hz},{ }^{4} J(\mathrm{H}, \mathrm{H})=1.1 \mathrm{~Hz}, 2 \mathrm{H}$; $\left.\mathrm{H} 2^{\prime}, 7^{\prime}\right), 6.86\left(\mathrm{~s}, 4 \mathrm{H} ; \mathrm{SO}_{2}\right.$ Mes-H3), $6.58\left(\mathrm{~d},{ }^{3} \mathrm{~J}(\mathrm{H}, \mathrm{H})=7.6 \mathrm{~Hz}, 2 \mathrm{H} ; \mathrm{H}^{\prime}, 8^{\prime}\right)$, 2.40 (s, $12 \mathrm{H} ; \mathrm{SO}_{2}$ Mes-C2- $\left.\mathrm{CH}_{3}\right), 2.26\left(\mathrm{~s}, 6 \mathrm{H} ; \mathrm{SO}_{2}\right.$ Mes-C4- $\left.\mathrm{CH}_{3}\right) \cdot{ }^{13} \mathrm{C}\left\{{ }^{1} \mathrm{H}\right\}$ NMR $\left(126 \mathrm{MHz}, \mathrm{CDCl}_{3}\right): \delta / \mathrm{ppm}=150.57$ (C2,7), 145.47 (C8'a,9'a), 143.92 (C4a,4b,8a,9a), 143.55 ( $\mathrm{SO}_{2}$ Mes-C4), 142.22 (C4'a,4'b), 139.92

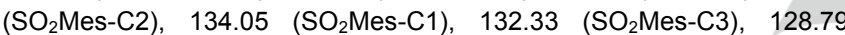
(C3',6'), 128.21 (C2', $\left.7^{\prime}\right), 126.93$ (C3,6), 123.60 (C1',8'), 123.01 (C1,8), 121.52 (C4,5), 120.90 (C4',5'), 66.18 (C9), $22.71\left(\mathrm{SO}_{2}\right.$ Mes-C2-CH $\mathrm{CH}_{3}$, $21.13\left(\mathrm{SO}_{2}\right.$ Mes-C4-CH $\left.{ }_{3}\right)$. IR (solid): $v / \mathrm{cm}^{-1}=2932(\mathrm{w}), 1605(\mathrm{w}), 1558$ $(w), 1443(m), 1396(w), 1381(w), 1304(s), 1180(w), 1165(w), 1142(s)$, $1126(\mathrm{~m}), 1072(\mathrm{~m}), 1034(\mathrm{w}), 1003(\mathrm{w}), 964(\mathrm{w}), 933(\mathrm{w}), 879(\mathrm{w})$ $864(\mathrm{w}), 849(\mathrm{w}), 818(\mathrm{w}), 764(\mathrm{~s}), 733(\mathrm{~m}), 717(\mathrm{~m}), 694(\mathrm{~s}), 663(\mathrm{~s}), 640$ (s), $617(\mathrm{w})$. UV/Vis $\left(\mathrm{MeCN}, 1.0 \times 10^{-5} \mathrm{~mol} \mathrm{dm}^{-3}\right): \lambda_{\max }(\varepsilon)=230(\mathrm{sh}$ 66000), 285 (44000), 297 (40000), $327 \mathrm{~nm}\left(14000 \mathrm{dm}^{3} \mathrm{~cm}^{-1} \mathrm{~mol}^{-1}\right)$. Fluorescence (MeCN, $1.0 \times 10^{-5} \mathrm{~mol} \mathrm{dm}^{-3}, \lambda_{\mathrm{ex}}=285 \mathrm{~nm}$ ): $\lambda_{\mathrm{em}}=421 \mathrm{~nm}$ $\mathrm{MS}(\mathrm{El}, 70 \mathrm{eV}): \mathrm{m} / \mathrm{z}=680.2[\mathrm{M}]^{+}(100$, calcd. 680.2).

2,7-Bis(pentylsulfonyl)-9,9'-spirobifluorene (SPSO3): 2,7-Dibromo9,9'-spirobi-ffluorene] (4.34 g, $9.14 \mathrm{mmol}), \mathrm{K}_{2} \mathrm{CO}_{3}(7.58 \mathrm{~g}, 54.9 \mathrm{mmol}, 6.0$ eq.) and 1-pentanthiol $(3.9 \mathrm{~mL}, 31.1 \mathrm{mmol}, 3.4$ eq.) was added to dry DMF $(4 \mathrm{~mL})$ and the suspension was stirred for $16 \mathrm{~h}$ at $140^{\circ} \mathrm{C}$. More 1 . pentanthiol $(9.14 \mathrm{mmol}, 1.0$ eq.) was added and the mixture was stirred for another $6 \mathrm{~h}$ at $140^{\circ} \mathrm{C}$. The mixture was poured into $\mathrm{H}_{2} \mathrm{O}$ and extracted with $\mathrm{CH}_{2} \mathrm{Cl}_{2}$. The combined organic layers were washed several times with $\mathrm{H}_{2} \mathrm{O}$ and dried over $\mathrm{Na}_{2} \mathrm{SO}_{4}$. The solvent was removed under reduced pressure and the crude bis-thioether $3(4.11 \mathrm{~g}, 86 \%)$ was used without further purification for the next step. Bis-thioether $3(2.5 \mathrm{~g}$, assuming $4.8 \mathrm{mmol}$ ) was dissolved in a mixture of $\mathrm{AcOH}(25 \mathrm{~mL})$, ethyl acetate $(40 \mathrm{~mL})$ and $\mathrm{H}_{2} \mathrm{O}_{2}(30 \%, 4.8 \mathrm{~mL}, 10.0$ eq). After stirring at room temperature for 2 days, $\mathrm{CHCl}_{3}(20 \mathrm{~mL})$ was added. The clear solution was stirred again at room temperature for 1 day and then at $40^{\circ} \mathrm{C}$ for 30 $\mathrm{min}$. The solvents were evaporated under reduced pressure and the residue was purified by column chromatography $\left(\mathrm{SiO}_{2}\right.$; ethyl acetate/cyclohexane, $2: 5 \rightarrow 4: 5$ ). The white product was further purified by recrystallization from dry EtOH. The fine white needles were filtered off and washed with pentane/diethylether (4:1). Yield: $1.54 \mathrm{~g}, 55 \% .{ }^{1} \mathrm{H}$ $\operatorname{NMR}\left(500 \mathrm{MHz}, \mathrm{CDCl}_{3}\right): \delta / \mathrm{ppm}=8.09\left(\mathrm{~d}, J=8.0 \mathrm{~Hz}, 2 \mathrm{H}, \mathrm{H}^{4,5}\right), 7.98(\mathrm{dd}$, $J=8.1,1.7 \mathrm{~Hz}, 2 \mathrm{H}, \mathrm{H}^{3,6}$ ), 7.88 (pseudo-dt, $J=7.6,0.9 \mathrm{~Hz}, 2 \mathrm{H}, \mathrm{H}^{4^{4} 5^{5}}$ ), 7.42 (pseudo-td, $\left.J=7.6,1.1 \mathrm{~Hz}, 2 \mathrm{H}, \mathrm{H}^{2,7}\right), 7.30\left(\mathrm{~d}, J=1.6 \mathrm{~Hz}, 2 \mathrm{H}, \mathrm{H}^{1,8}\right)$,
7.11 (pseudo-td, $J=7.5,1.1 \mathrm{~Hz}, 2 \mathrm{H}, \mathrm{H}^{3: 6^{4}}$ ), 6.62 (pseudo-dt, $J=7.7,0.9$ $\left.\mathrm{Hz}, 2 \mathrm{H}, \mathrm{H}^{1,8}\right), 2.99-2.87\left(\mathrm{~m}, 4 \mathrm{H}, \mathrm{H}^{\mathrm{sO} 2 \mathrm{C} 2} 2\right), 1.61-1.50(\mathrm{~m}, 4 \mathrm{H}$, $\left.\mathrm{H}^{\mathrm{SO} 2 \mathrm{CH} 2 \mathrm{CH} 2}\right), 1.28-1.11\left(\mathrm{~m}, 8 \mathrm{H}, \mathrm{H}^{\mathrm{CH} 2}\right), 0.78\left(\mathrm{t}, \mathrm{J}=7.1 \mathrm{~Hz}, 6 \mathrm{H}, \mathrm{H}^{\mathrm{CH} 3}\right)$. ${ }^{13} \mathrm{C}\left\{{ }^{1} \mathrm{H}\right\}$ NMR $\left(126 \mathrm{MHz}, \mathrm{CDCl}_{3}\right): \delta / \mathrm{ppm}=151.4\left(\mathrm{C}^{2,7}\right), 145.5\left(\mathrm{C}^{4^{\prime} \mathrm{a}, 4^{4} \mathrm{~b}}\right)$, $144.8\left(C^{4 a, 4 b}\right), 142.2\left(C^{8 a}, 9^{\prime a}\right), 140.1\left(C^{8 a, 9 a}\right), 129.0\left(C^{2^{\prime}, 7^{7}}\right), 128.5\left(C^{3,6}\right)$, $128.4\left(C^{3^{\prime}, 6^{\prime}}\right), 124.4\left(C^{1,8}\right), 123.7\left(C^{1^{1,8}}\right), 121.8\left(C^{4,5}\right), 120.9\left(C^{4^{\prime}, 5^{\prime}}\right), 66.1$ $\left(\mathrm{C}^{9}\right), 56.4\left(\mathrm{C}^{\mathrm{SO} 2} \underline{\mathrm{CH}} 2\right), 30.3\left(\mathrm{C}^{\mathrm{CH} 2}\right), 22.3\left(\mathrm{C}^{\mathrm{SO} 2 \mathrm{CH} 2} \underline{\mathrm{CH}} 2\right), 22.1\left(\mathrm{C}^{\mathrm{CH} 2}\right), 13.7$ $\left(\mathrm{C}^{\mathrm{CH} 3}\right)$. UV/Vis (MeCN, $\left.1.0 \times 10^{-5} \mathrm{~mol} \mathrm{dm}{ }^{-3}\right): \lambda_{\max }(\varepsilon)=197$ (47650), 211 (51000), 223 (sh, 42400), 259 (sh, 27500), 277 (36700), 290 (29800), 304 (966), $318 \mathrm{~nm}\left(6900 \mathrm{dm}^{3} \mathrm{~cm}^{-1} \mathrm{~mol}^{-1}\right)$. MS (MALDI-TOF, without matrix): $m / z(\%)=585.5[M]^{+}$(calcd. 584.2). Anal. calcd. For $\mathrm{C}_{35} \mathrm{H}_{36} \mathrm{O}_{4} \mathrm{~S}_{2}$. C 71.88, H 6.20; found: C 71.65, H 6.37. Fluorescence (MeCN, $1.0 \times 10^{-}$ $\left.{ }^{5} \mathrm{~mol} \mathrm{dm}^{-3}\right): \lambda_{\mathrm{em}}=422 \mathrm{~nm}$.

Crystallography: Data were collected on a Bruker-Nonius KappaAPEX diffractometer with data reduction, solution, and refinement by using the programs APEX2. ${ }^{[22]}$ Mercury v. $3.1^{[23]}$ was used to analyze and display the X-ray structures.

SPSO1.2 $\mathrm{CH}_{2} \mathrm{Cl}_{2}: \mathrm{C}_{39} \mathrm{H}_{28} \mathrm{Cl}_{4} \mathrm{O}_{4} \mathrm{~S}_{2}, M=766.59$, colorless block, monoclinic, space group $P 2_{1} / c, a=11.9690(6), b=12.9602(6), c=23.1478(11) \AA, \beta$ $=93.801(3)^{\circ}, U=3582.8(3) \AA^{3}, Z=4, D_{c}=1.421 \mathrm{Mg} \mathrm{m}^{-3}, \mu(\mathrm{Mo}-\mathrm{K \alpha} \alpha)=$ $0.488 \mathrm{~mm}^{-1}, T=123 \mathrm{~K}$. Total 89315 reflections, 13057 unique, $R_{\text {int }}=$ 0.036 . Refinement of 9162 reflections (498 parameters) with $I>2 \sigma(I)$ converged at final $R 1=0.0572(R 1$ all data $=0.0744), w R 2=0.0597$ $(w R 2$ all data $=0.0968)$, gof $=1.0852 . \operatorname{CCDC} 974892$

SPSO2: $\mathrm{C}_{43} \mathrm{H}_{36} \mathrm{O}_{4} \mathrm{~S}_{2}, M=680.89$, colorless block, monoclinic, space group $C 2 / c, a=19.2422(4), b=15.6495(4), c=13.1743(3) \AA, \beta=$ 123.096(2) ${ }^{\circ}, U=3323.54(15) \AA^{3}, Z=4, D_{c}=1.361 \mathrm{Mg} \mathrm{m}^{-3}, \mu(\mathrm{Mo}-\mathrm{K} \alpha)=$ $0.206 \mathrm{~mm}^{-1}, T=173 \mathrm{~K}$. Total 21904 reflections, 6040 unique, $R_{\text {int }}=0.036$. Refinement of 4110 reflections (222 parameters) with $I>2 \sigma(I)$ converged at final $R 1=0.0458(R 1$ all data $=0.0610), w R 2=0.0484(w R 2$ all data $=$ $0.0775)$, gof $=1.0852$. CCDC 974893 .

SPSO3: $\mathrm{C}_{35} \mathrm{H}_{36} \mathrm{O}_{4} \mathrm{~S}_{2}, M=584.80$, colorless plate, monoclinic, space group $c 2 / c, a=19.5503(8), b=10.7566(4), c=15.8860(7) \AA, \beta=$ 118.486(2) ${ }^{\circ}, U=2936.3(2) \AA^{3}, Z=4, D_{c}=1.323 \mathrm{Mg} \mathrm{m}^{-3}, \mu(\mathrm{Cu}-\mathrm{K} \alpha)=$ $0.488 \mathrm{~mm}^{-1}, T=123 \mathrm{~K}$. Total 11690 reflections, 2698 unique, $R_{\mathrm{int}}=0.033$. Refinement of 2380 reflections (186 parameters) with $I>2 \sigma(I)$ converged at final $R 1=0.0376(R 1$ all data $=0.0404), w R 2=0.0400 \quad(w R 2$ all data $=0.0487)$, gof $=1.0884$. CCDC 993287

Theoretical calculations: Density functional calculations (DFT) were carried out with the D.01 revision of the Gaussian 09 program package ${ }^{[24]}$ by using Becke's three-parameter B3LYP exchange-correlation functional ${ }^{[25]}$ together with the $6-31 \mathrm{G}^{* *}$ basis set for $\mathrm{H}, \mathrm{C}, \mathrm{S}, \mathrm{O}$, and $\mathrm{P}^{[26]}$ and the "double-z" quality LANL2DZ basis set for the Ir element. ${ }^{[2]}$ The geometries of the singlet ground state $\left(\mathrm{S}_{0}\right)$ and the lowest-energy singlet $\left(\mathrm{S}_{1}\right)$ and triplet $\left(\mathrm{T}_{1}\right)$ states were fully optimized without imposing any symmetry restriction. All the calculations were performed in the presence of the solvent (acetonitrile). Solvent effects were considered within the self-consistent reaction field (SCRF) theory by using the polarized continuum model (PCM) approach. ${ }^{[28]}$ Time-dependent DFT (TD-DFT) calculations of the lowest-lying 20 singlets and triplets were performed in the presence of the solvent at the minimum-energy geometry optimized for $S_{0}$. The geometry of the $S_{1}$ singlet state was optimized at the TD-DFT level and that of the $T_{1}$ triplet state at the spin-unrestricted UB3LYP level.

LEC Device preparation and characterization: The solvents were supplied by Aldrich. The thickness of films was determined with an Ambios XP-1 profilometer. Indium tin oxide ITO glass plates were patterned by conventional photolithography. The 
substrates were cleaned by sonication in water-soap, water, and isopropanol baths. After drying, the substrates were placed in a UV-ozone cleaner (Jelight 42-220) for $20 \mathrm{~min}$. The blue phosphorecent devices were made as follows. First, a 70-80 nm layer of PEDOT/PSS (CLEVIOS P VP Al 4083, Heraeus) was spin-coated on the ITO substrates to improve the reproducibility. The synthesized acceptor-hosts were dissolved in anisole, followed by dissolving the hole-transporting hosts NMS25 (see Supporting Information for structure) or TCTA (Lumtec, see Supporting Information for structutre) and 10\% Flrpic (Lumtec) as the dopant. The total concentration of dissolved hosts and dopants was $20 \mathrm{mg} / \mathrm{mL}$. In the LEC 5 , a molar ratio of the hostFirPic blend and the ionic liquid $\left[\mathrm{THA}^{+}\left[\mathrm{BF}_{4}\right]^{-}\right.$(Sigma Aldrich) was

8:1.

The device life-time was measured by applying pulsed current (average: $100 \mathrm{~A} \mathrm{~m}^{-2}$ ) with a duty cycle of $50 \%$ and monitoring the average voltage and luminance by a True Colour Sensor MAZeT (MTCSiCT Sensor) with a Botest OLT OLED LifetimeTest System

\section{Acknowledgements}

We thank the Swiss National Science Foundation, the University of Basel, the Spanish Ministry of Economy and Competitiveness (MINECO) (MAT2014-55200, CTQ2012-31914, CTQ201571154, and Unidad de Excelencia María de Maeztu MDM-20150552), the Generalitat Valenciana (Prometeo/2012/053), the European Research Council (Advanced Grant 267816 LiLo), and European FEDER funds (CTQ2012-31914) for financial support. PD Dr. Daniel Häussinger is thanked for assistance with the NMR spectroscopy.

[1] a) Y. Tao, C. Yang, J. Qin, Chem. Soc. Rev. 2011, 40, 2943-2970; b) H. Sasabe, J. Kido, J. Mater. Chem. C 2013, 1, 1699-1707; c) B. W. D'Andrade, S. R. Forrest, Adv. Mater. 2004, 16, 1585-1595.

[2] M. A. Baldo, D. F. O'Brien, Y. You, A. Shoustikov, S. Sibley, M. E. Thompson, S. R. Forrest, Nature 1998, 395, 151-154.

[3] L. S. Sapochak, A. B. Padmaperuma, P. A. Vecchi, H. Qiao, P. E. Burrows, in Proc. SPIE, 2006, p. 63330.

[4] a) S. E. Jang, C. W. Joo, J. Y. Lee, Thin Solid Films 2010, 519, 906910; b) S. O. Jeon, K. S. Yook, C. W. Joo, J. Y. Lee, Adv. Mater. 2010, 22, 1872-1876; c) B. Zhang, G. Tan, C.-S. Lam, B. Yao, C.-L. Ho, L. Liu, Z. Xie, W.-Y. Wong, J. Ding, L. Wang, Adv. Mater. 2012, 24, 18731877; d) S. Shao, J. Ding, L. Wang, X. Jing, F. Wang, J. Am. Chem. Soc. 2012, 134, 20290-20293; e) B. Zhang, L. Liu, G. Tan, B. Yao, C.-L. Ho, S. Wang, J. Ding, Z. Xie, W.-Y. Wong, L. Wang, J. Mater. Chem. C 2013, 1, 4933-4939.

[5] a) S. O. Jeon, J.-H. Kim, J. W. Kim, Y. Park, J. Y. Lee, J. Phys. Chem. C 2011, 115, 18789-18794; b) S. O. Jeon, K. S. Yook, J. Y. Lee, S. M. Park, J. Won Kim, J.-H. Kim, J.-A. Hong, Y. Park, Appl. Phys. Lett. 2011, 98.

[6] A. Pertegás, N. M. Shavaleev, D. Tordera, E. Ortí, M. K. Nazeeruddin, H. J. Bolink, J. Mater. Chem. C. 2014, 1605-1611.

[7] S.-J. Kim, J. Leroy, C. Zuniga, Y. Zhang, L. Zhu, J. S. Sears, S. Barlow, J.-L. Brédas, S. R. Marder, B. Kippelen, Org. Electron. 2011, 12, 13141318.
[8] H. Sasabe, Y. Seino, M. Kimura, J. Kido, Chem. Mater. 2012, 24, 14041406.

[9] a) X. Yang, G. Zhou, W.-Y. Wong, Chem. Soc. Rev. 2015, 44,84848575 and references therein; b) M. P. Gaj, C. Fuentes-Hernandez, Y. Zhang, S. R. Marder, B. Kippelen, Org. Electron. 2015, 16, 109-112; c) M. Romain, D. Tondelier, B. Geffroy, A. Shirinskaya, O. Jeannin, J. Rault-Berthelot, C. Poriel, Chem. Commun. 2015, 51, 1313-1315; d) S. O. Jeon, T. Earmme, S. A. Jenekhe, J. Mater. Chem. C 2014, 2, 1012910137; e) Y. P. Jeon, K. S. Kim, K. K. Lee, I. K. Moon, D. C. Choo, J. Y Lee, T. W. Kim, J. Mater. Chem. C 2105, 3, 6192-6199; f) Y. Li, X.-L. Li, X. Cai, D. Chen, X. Liu, G. Xie, Z. Wang, Y.-C. Wu, C.-C. Lo, A. Lien, J. Peng, Y. Cao, S.-J. Sun, J. Mater. Chem. C 2105, 3, 6986-6996; g) Y. Li, Z. Wang, X. Li, G. Xie, D. Chen, Y.-F. Wang, C.-C. Lo, A. Lien, J. Peng, Y. Cao, S.-J. Su, Chem. Mater. 2015, 27, 1100-1109; h) C.-Y. Chan, Y.-C. Wong, M.-Y. Chan, S.-H. Cheung, S.-K. So, V.W.-W. Yam, Chem. Mater. 2014, 26, 6585-6594; i) W. Song, I. Lee, J. Y. Lee, Adv. Mater. 2015, 27, 4358-4363.

[10] F.-M. Hsu, C.-H. Chien, Y.-J. Hsieh, C.-H. Wu, C.-F. Shu, S.-W. Liu, C.T. Chen, J. Mater. Chem. 2009, 19, 8002-8008.

[11] a) W. Lee, W. S. Jenks, J. Org. Chem. 2001, 66, 474-480; b) W. S. Jenks, W. Lee, D. Shutters, J. Phys. Chem. 1994, 98, 2282-2289.

[12] T. P. I. Saragi, T. Spehr, A. Siebert, T. Fuhrmann-Lieker, J. Salbeck, Chem. Rev. 2007, 107, 1011-1065.

[13] a) D. Vonlanthen, J. Rotzler, M. Neuburger, M. Mayor, Eur. J. Org. Chem. 2010, 2010, 120-133; b) D. Vonlanthen, A. Mishchenko, M. Elbing, M. Neuburger, T. Wandlowski, M. Mayor, Angew. Chem. Int. Ed. 2009, 48, 8886-8890.

[14] a) H. Golchoubian, F. Hosseinpoor, Molecules 2007, 12, 304-311; b) P Gao, X. Feng, X. Yang, V. Enkelmann, M. Baumgarten, K. Müllen, J. Org. Chem. 2008, 73, 9207-9213.

[15] J. Clayden, J. Senior, M. Helliwell, Angew. Chem. Int. Ed. 2009, 48, 6270-6273.

[16] F. M. Rudolph, A. Fuller, A. Z. Slawin, M. Bühl, R. A. Aitken, J. D Woollins, J. Chem. Crystallogr. 2010, 40, 253-265.

[17] C. Hansch, A. Leo, R. W. Taft, Chem. Rev. 1991, 91, 165-195.

[18] S. J. Yeh, M. F. Wu, C. T. Chen, Y. H. Song, Y. Chi, M. H. Ho, S. F. Hsu, C. H. Chen, Adv. Mater. 2005, 17, 285-289.

[19] a) J. D. Slinker, J. A. DeFranco, M. J. Jaquith, W. R. Silveira, Y.-W. Zhong, J. M. Moran-Mirabal, H. G. Craighead, H. D. Abruna, J. A. Marohn, G. G. Malliaras, Nat. Mater. 2007, 6, 894-899; b) P. Matyba, K. Maturova, M. Kemerink, N. D. Robinson, L. Edman, Nat. Mater. 2009, 8, 672-676.

[20] a) L. He, L. Duan, J. Qiao, R. Wang, P. Wei, L. Wang, Y. Qiu, Adv. Funct. Mater. 2008, 18, 2123-2131; b) F. D. D. B. D. Gigmes, Int. J. Nanotech. 2012, 9, 377 - 395.

[21] C.-T. Liao, H.-F. Chen, H.-C. Su, K.-T. Wong, Phys. Chem. Chem. Phys. 2012, 14, 1262-1269.

[22] Analytical X-ray Systems, I. Bruker, APEX2, version 2, User Manual, M86-E01078, Madison, WI, 2006.

[23] C. F. Macrae, I. J. Bruno, J. A. Chisholm, P. R. Edgington, E. P. P. McCabe, L. Rodriguez-Monge, R. Taylor, J. v. d. Streek, P. A. Wood, J. Appl. Cryst. 2008, 41, 466-470.

[24] Gaussian 09, Revision D.01, M. J. Frisch, G. W. Trucks, H. B. Schlegel, G. E. Scuseria, M. A. Robb, J. R. Cheeseman, G. Scalmani, V. Barone B. Mennucci, G. A. Petersson, H. Nakatsuji, M. Caricato, X. Li, H. P. Hratchian, A. F. Izmaylov, J. Bloino, G. Zheng, J. L. Sonnenberg, M Hada, M. Ehara, K. Toyota, R. Fukuda, J. Hasegawa, M. Ishida, T. Nakajima, Y. Honda, O. Kitao, H. Nakai, T. Vreven, J. Montgomery, J. A., J. E. Peralta, F. Ogliaro, M. Bearpark, J. J. Heyd, E. Brothers, K. N. Kudin, V. N. Staroverov, R. Kobayashi, J. Normand, K. Raghavachari, A. Rendell, J. C. Burant, S. S. lyengar, J. Tomasi, M. Cossi, N. Rega, J. M. Millam, M. Klene, J. E. Knox, J. B.Cross, V. Bakken, C. Adamo, J. Jaramillo, R. Gomperts, R. E. Stratmann, O. Yazyev, A. J. Austin, R. Cammi, C. Pomelli, J. W. Ochterski, R. L. Martin, K. Morokuma, V. G. Zakrzewski, G. A. Voth, P. Salvador, J. J. Dannenberg, S. Dapprich, A. 
D. Daniels, Ö. Farkas, J. B. Foresman, J. V. Ortiz, J. Cioslowski, D. J Fox, Gaussian, Inc., Wallingford CT, 2010

[25] a) C. T. Lee, W. T. Yang, R. G. Parr, Phys. Rev. B 1988, 37, $785-789$ b) A. D. Becke J. Chem. Phys. 1993, 98, $5648-5652$.

[26] M. M. Francl, W. J. Pietro, W. J. Hehre, J. S. Binkley, M. S. Gordon, D. J. Defrees, J. A. Pople, J. Chem. Phys. 1982, 77, $3654-3665$.

[27] P. J. Hay, W. R. Wadt, J. Chem. Phys. 1985, 82, $299-310$
[28] a) J. Tomasi, M. Persico, Chem. Rev. 1994, 94, 2027 - 2094; b) C. S. Cramer, D. G. Truhlar, Solvent Effects and Chemical Reactivity, Kluwer, Dordrecht, 1996, pp. 1-80; c) J. Tomasi, B. Mennucci, R. Cammi, Chem. Rev. 2005, 105, 2999 - 3093.

Received: ((will be filled in by the editorial staff))

Revised: ((will be filled in by the editorial staff))

Published online: ((will be filled in by the editorial staff)) 
Entry for the Table of Contents (Please choose one layout)

\section{FULL PAPER}

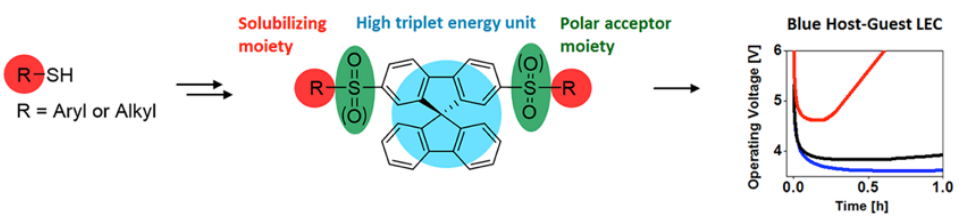

Bis-sulfone- and bis-sulfoxide-spirobifluorenes are a promising class of high-tripletenergy electron-acceptor-hosts for blue phosphorescent light-emitting devices. The molecular design and synthetic route is simple and allows tailoring the solubility of hosts without lowering the high-energy triplet state. A series of polar acceptor hosts has been synthesized and tested in LECs. Large effects of the various solubilizing moieties on the LEC performance were observed and are discussed.
Topic: Host materials in LECs

Cathrin D. Ertl, Henk Bolink, Catherine E. Housecroft, ${ }^{\star}$ Edwin C. Constable, Enrique Ortí, José M. JunqueraHernández, Markus Neuburger, Nail M. Shavaleev, Mohammad Khaja Nazeeruddin, David Vonlanthen*

Bis-Sulfone- and Bis-SulfoxideSpirobifluorenes: Polar AcceptorHosts with tunable Solubilities for Blue-Phosphorescent Light-Emitting Device 